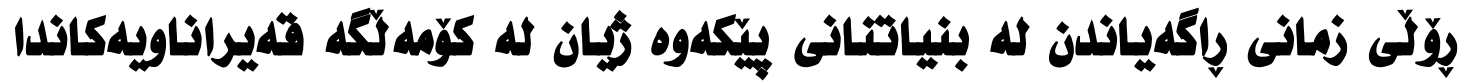

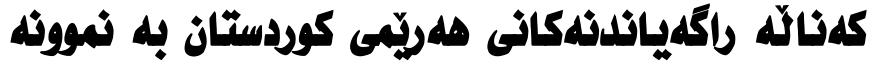

نهزاكهت حسيّز حهمdسلعيد

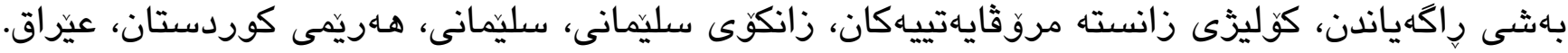
nazakat.hamasaeed@univsul.edu.iq :يمـاهيل:

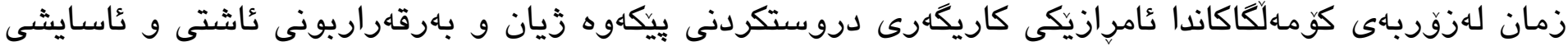

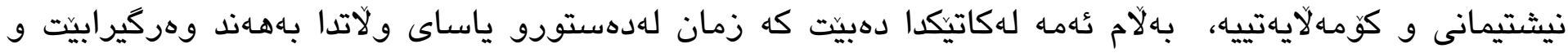

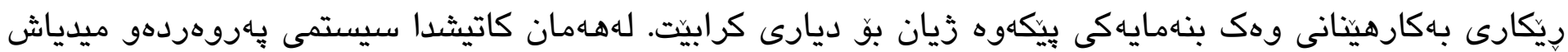

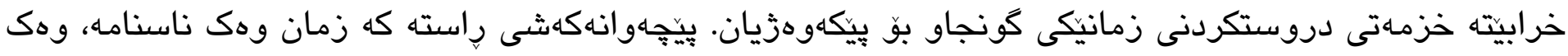

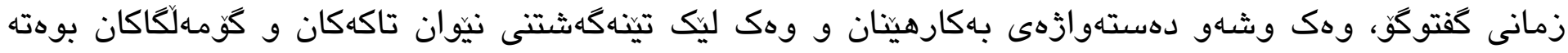

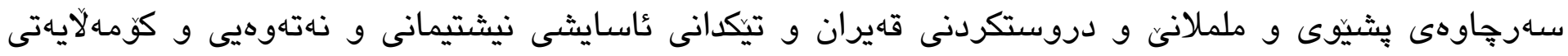

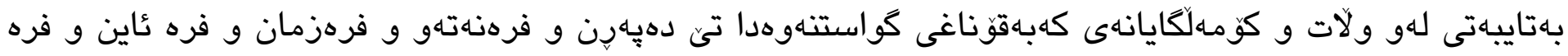

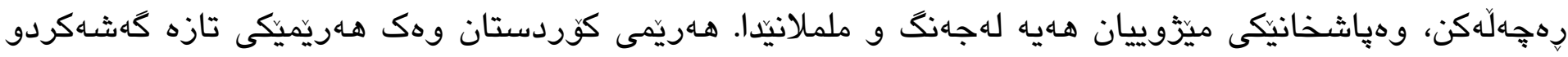

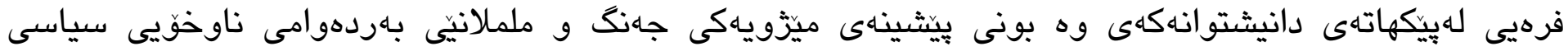

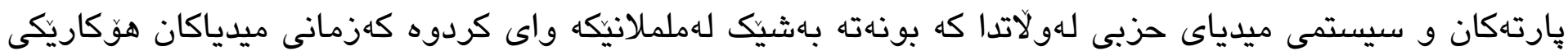

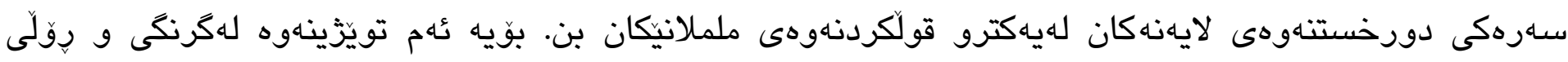

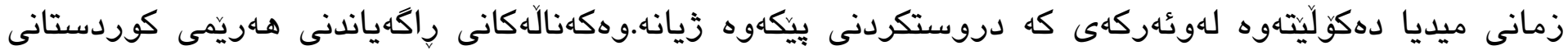

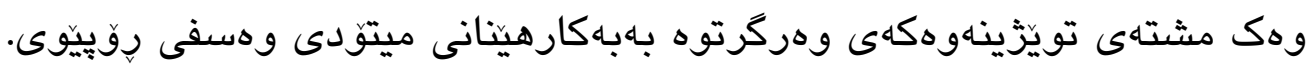

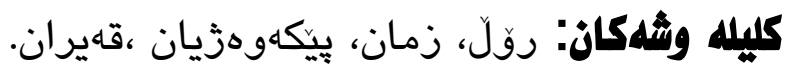




\section{بلاشى يلهكم :ميتوّدنامه}

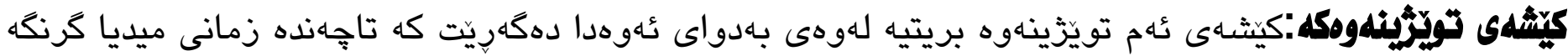

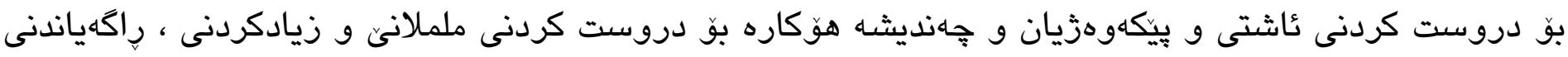

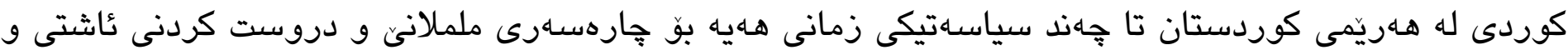
ي ينكاهوهزيان.

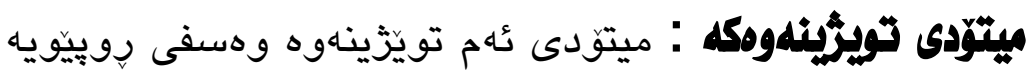

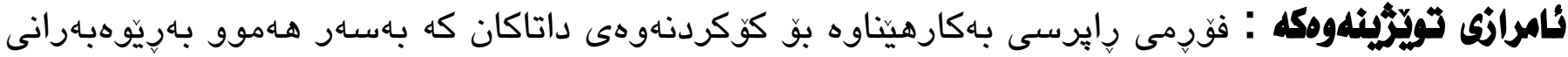

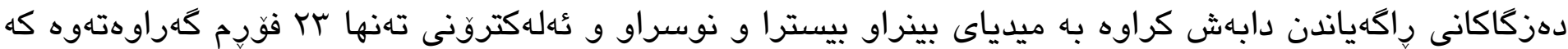

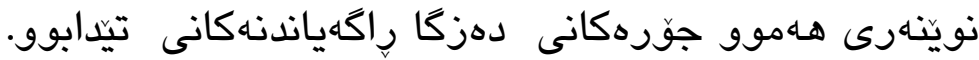

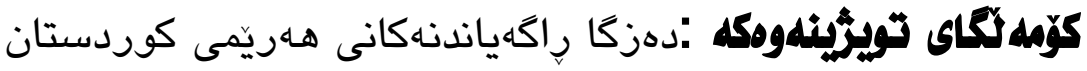

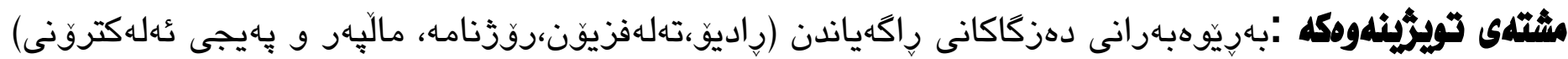
كرنكى تورئرينهومكه:

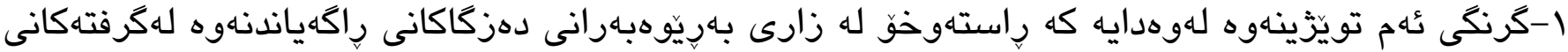

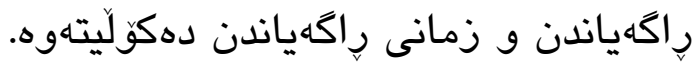

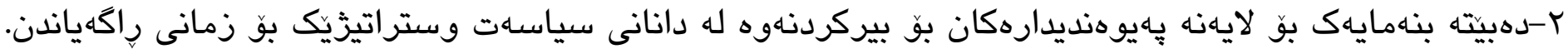

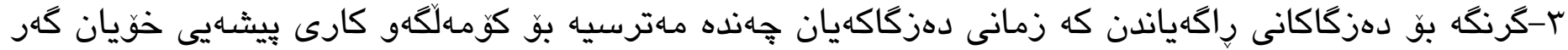
سياسهتيكى زمانى ناهتوهيى نيشتمانيان نابيت.

\section{هربسياروكاذى تويرئنهومكه}

ا-ئايا زمانى رِاكهياندن تواناى ههيه ململاني و قهيران كهم بكاتهوه؟

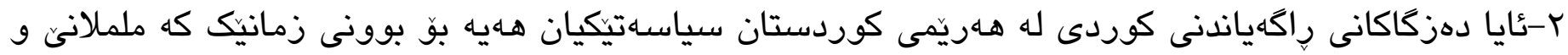

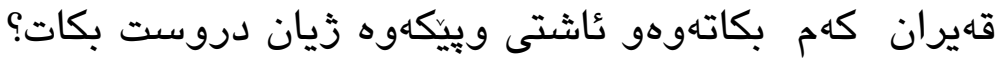




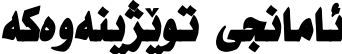

ا-دهيهاويت دهريخات تاجهنده زمانى راكهياندن هوَكاره بو دروست كردنى عاشتى و بيّكهوهزيان وكهم كردنهوهى ململاني. צ-دهرخستنى كرفتهكانى راكهياندنى كوردى لهبوونى سياسهتيكى زمانى كه خزماهتى عاسايسى نهتهوهيى و نيشتمانى و كومهالايهتى بكات.

ז-زانينى بوونى سياسهتى زمانى رِاكهياندنى كوردى بو دروست كردنى ئاشتى ويِكاهوهزيان و كهم كردنهوهى ململانى

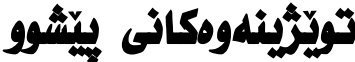

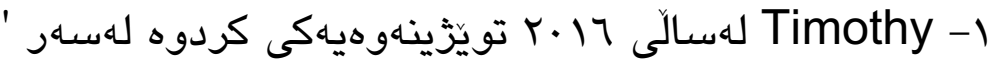
Language and communication conflict in Nigeria: Communicative language pedagogy 'باسى جياوازى باكگراوندى دانيشتوانى نايجيريا دهكات، جِّن رهنكدانهوهى هـبوه لهسهر Implications for

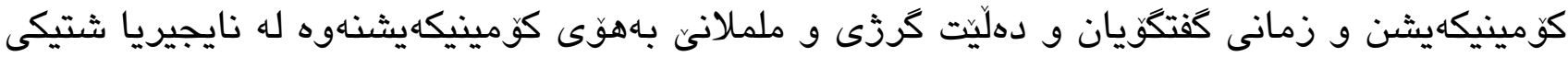

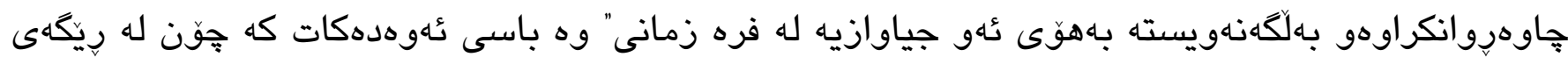

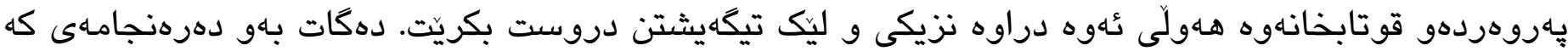

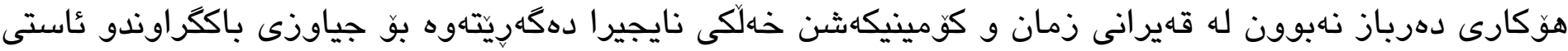

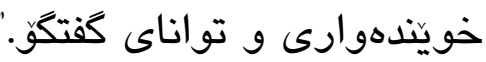

Democratic Progress Instituter. 1 - لهسالى 1 The Role of Language, Identity' تويّزينهوهيهكى كرد لهسئ

and the Media in Conflict Resolution

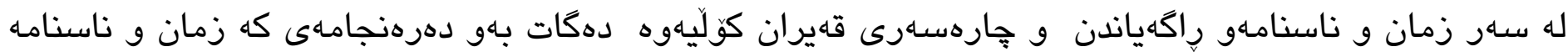

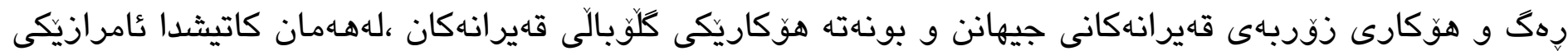

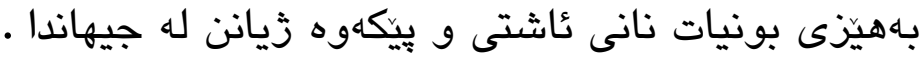

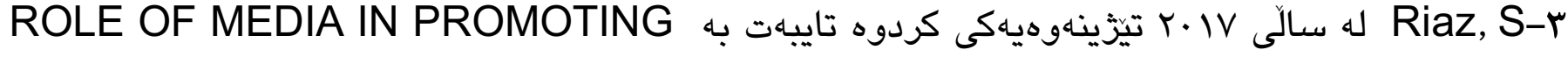
PEACE AND HARMONY

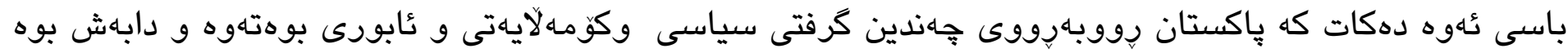

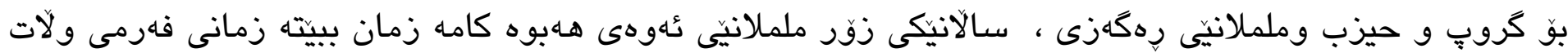


،دهكات بهو دهرهنجامهى كه ميديا رِوّلى كَنك دهبينيتّ له دروست كردنى ئاشتى و بِيَكهوهزيان به ئامادهردنى

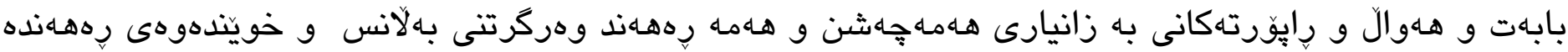

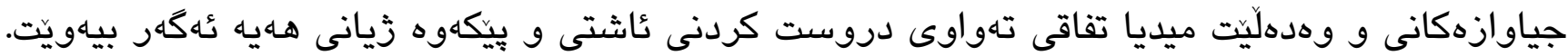

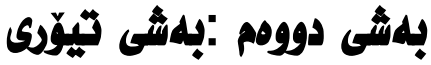

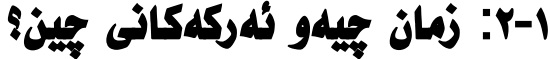

Siddiq, M. دلّيت" زمان تهنها ناوهنديكى سادهى كهياندنى كومينيكهيشن نيه بهلكو هـلَّكى مانا و كلتورو بهاهايه

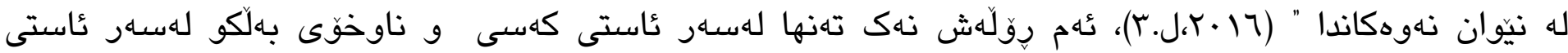

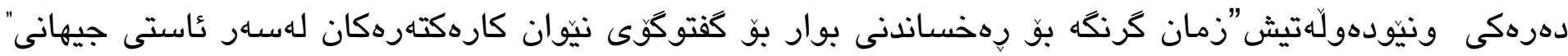
. (Y. •. ACHIENG)

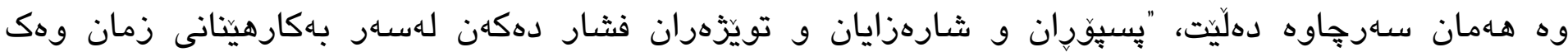

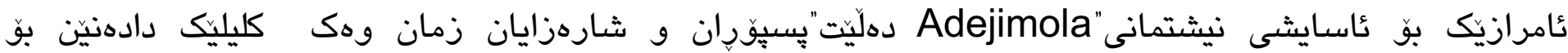

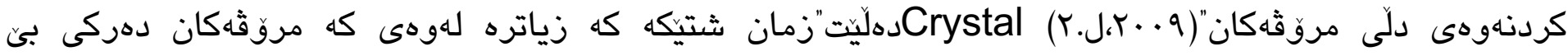

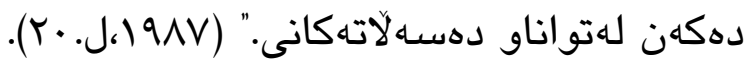

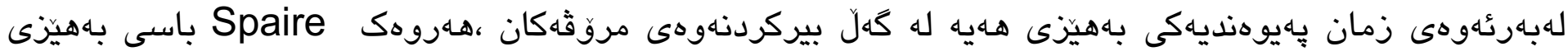

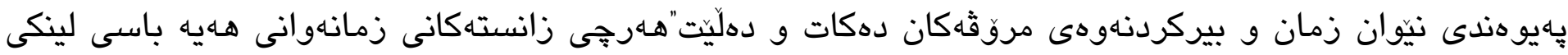

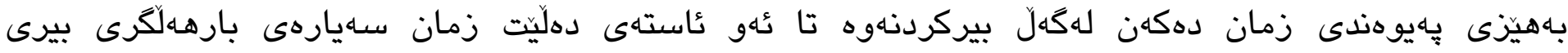

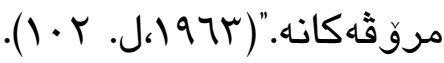

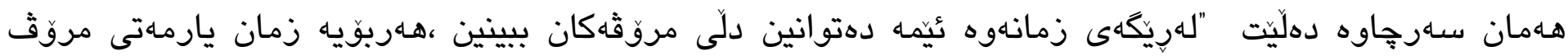

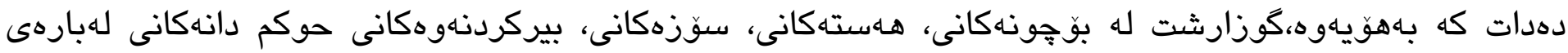

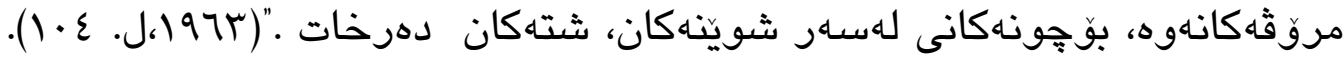
Adejimola.

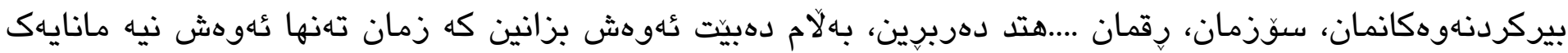

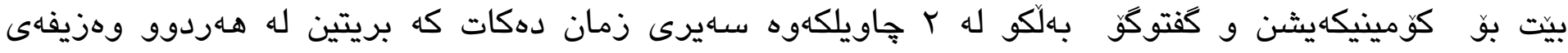

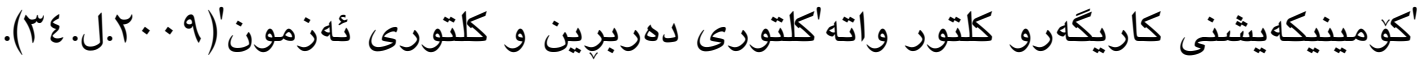

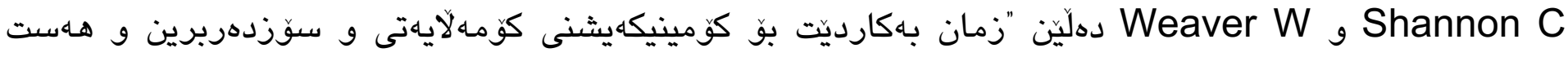

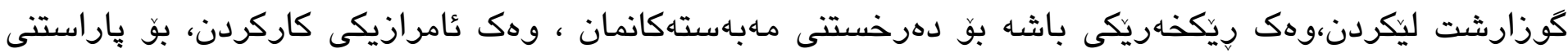


توماركراوهكان وكواستناوهى زانياريـكان و فهرمان دهركردنهكان واته وهك تُهرشيفيك،بو كاريكَرى كردن و وه

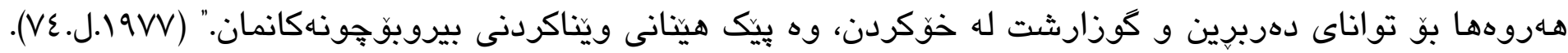

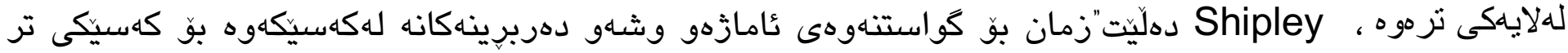

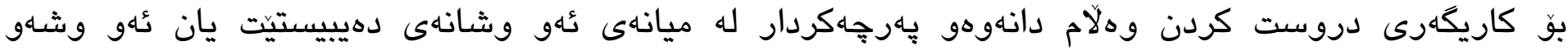

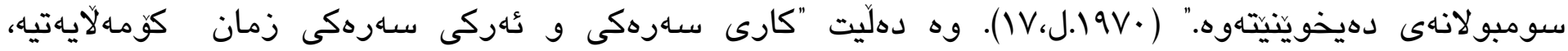

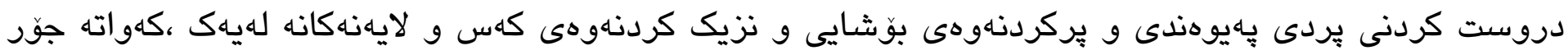

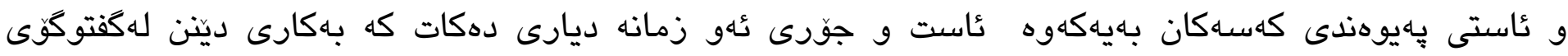

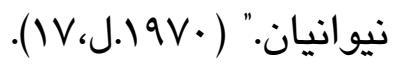

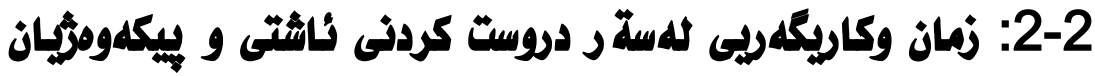

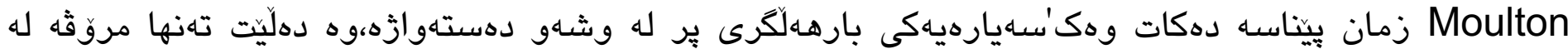

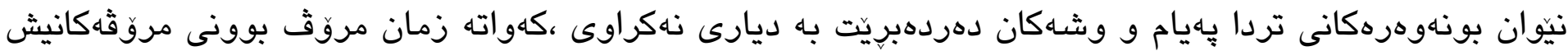

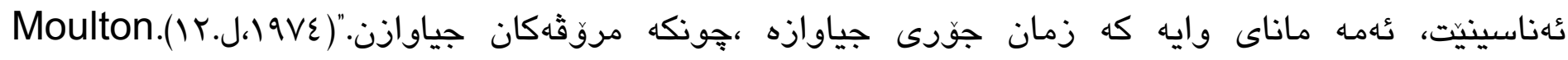

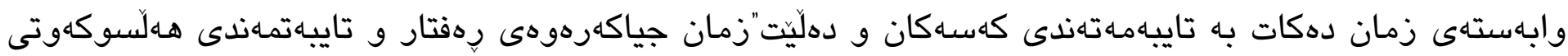

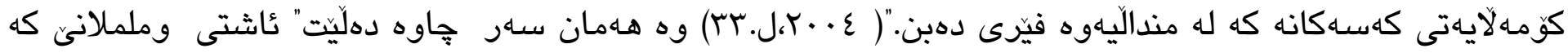

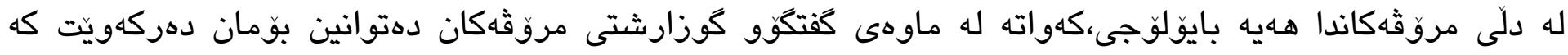

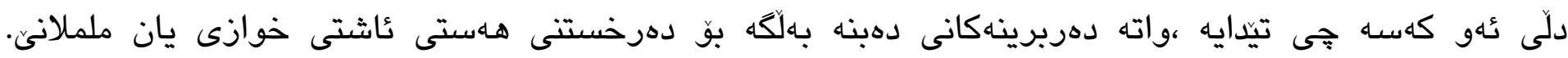

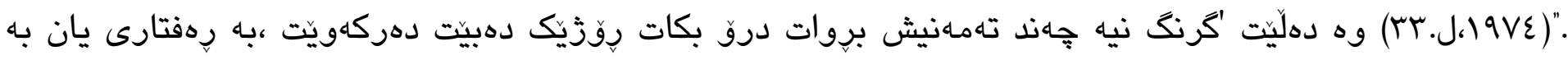

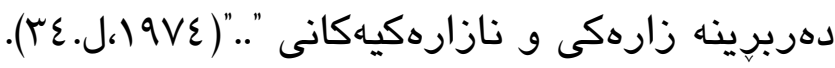

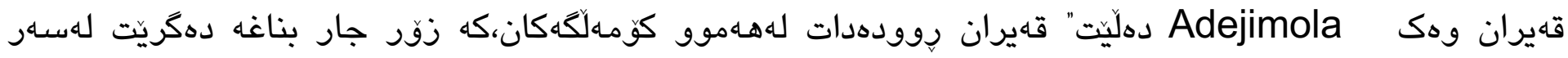

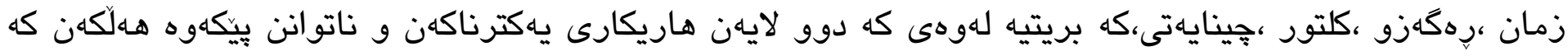

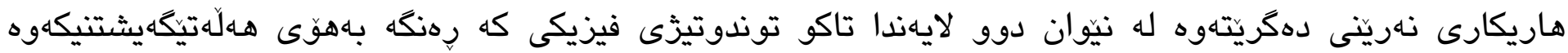

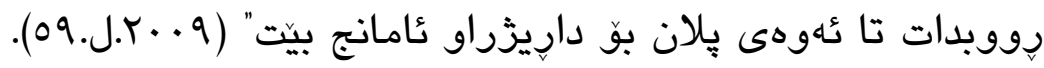

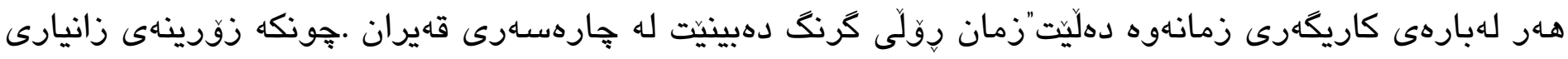

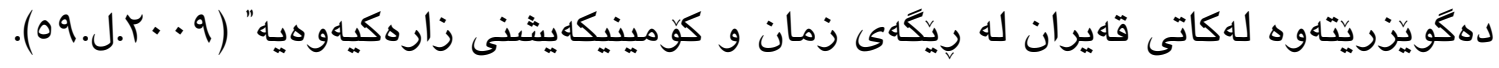




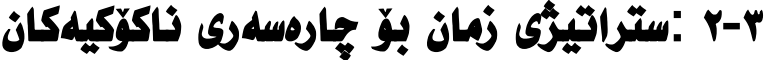

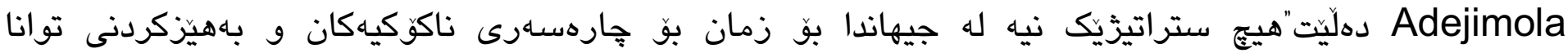

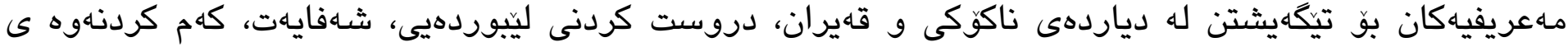

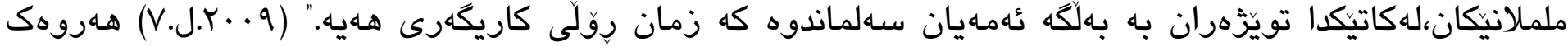

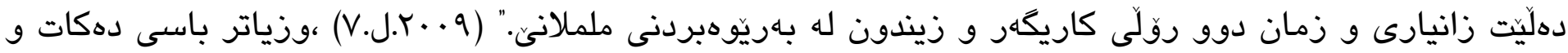

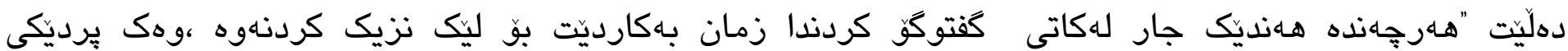

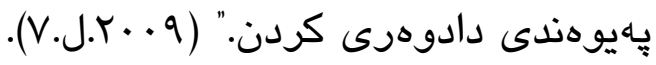

"زمان كَويزهرهوهى بيروكهو عُايديايه، نايدياش دهتوانريّت بهكاربيت بوّ ليك نزيك بونهوهو تيكهيشتن له

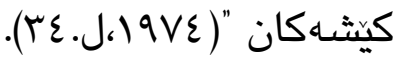

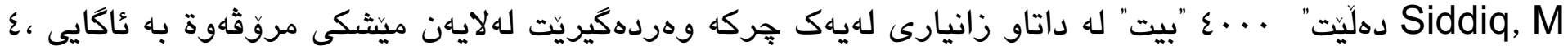

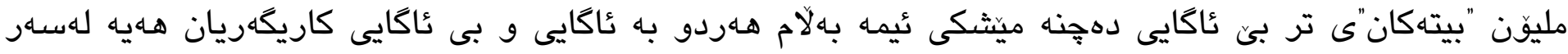

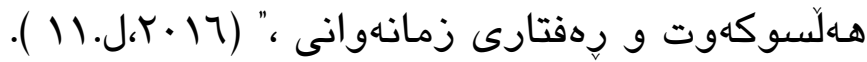

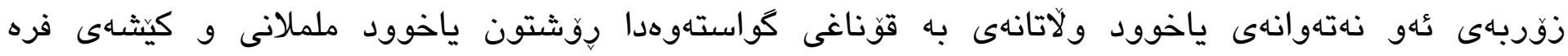

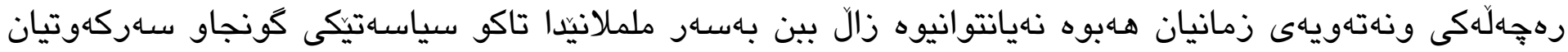

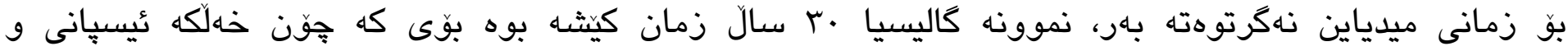

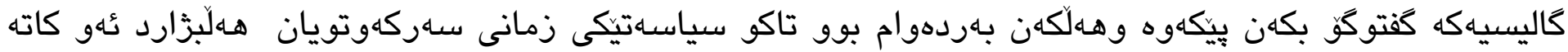
ئاشتى بهرقهرار بووو له كومهلكَهدا.

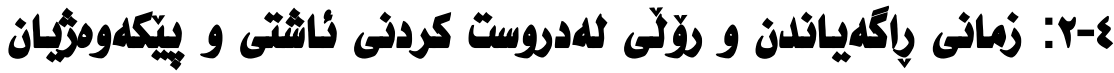

Shannon and Weaver

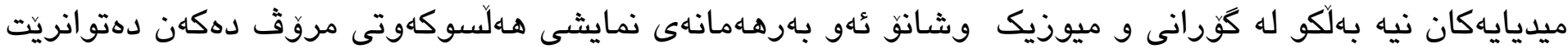

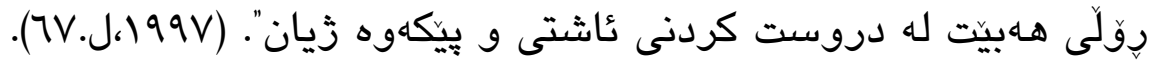

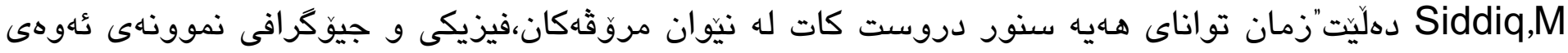

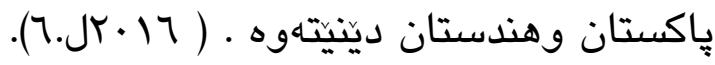
Pagel, M.

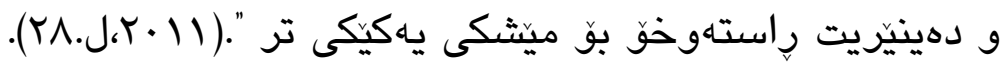




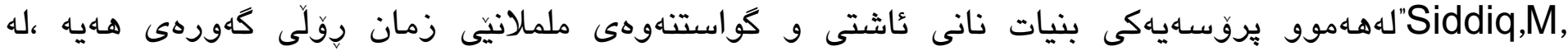

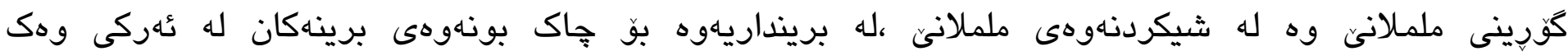

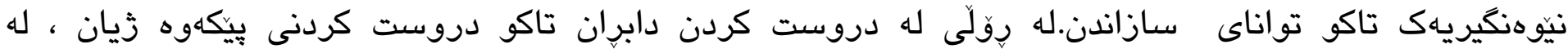

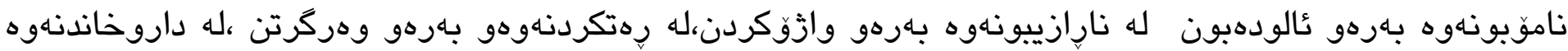

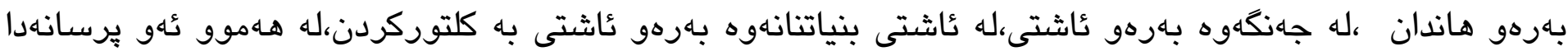

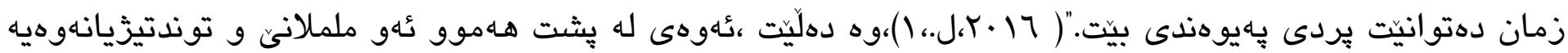

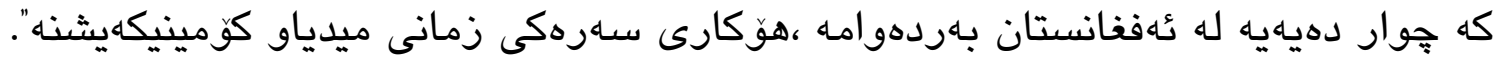

Elworthy.

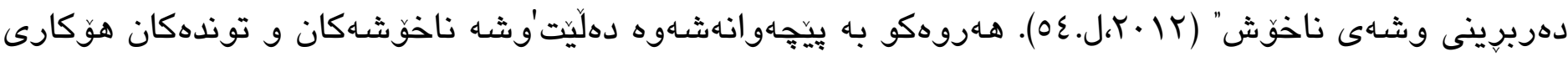

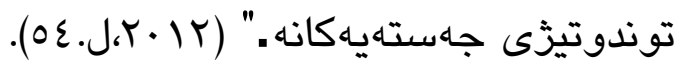

FFairclough

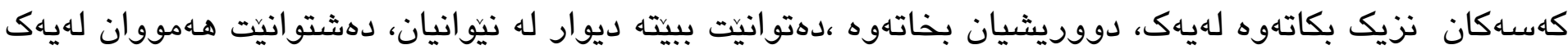

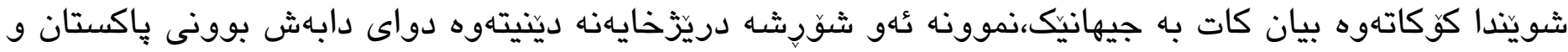
دواتر دروست بوونى بهنكلاديش، دواتر داواى ناساندنى زمانى بانكلاديشى وهك زمانى دوهمى فهرمى ولآت، كه له له

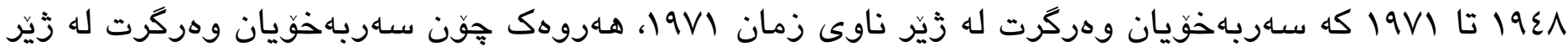

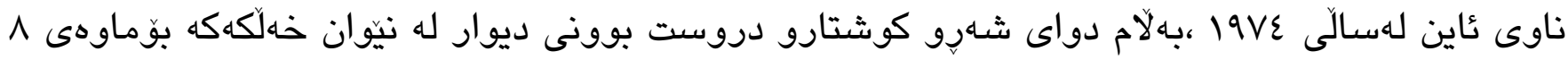

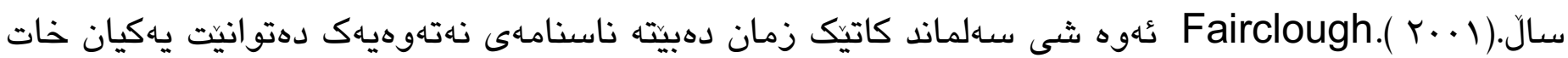

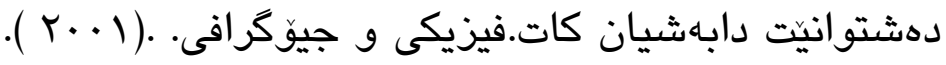

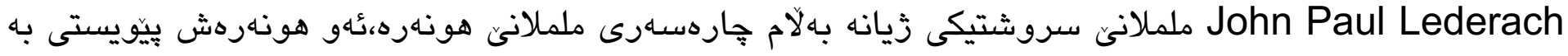

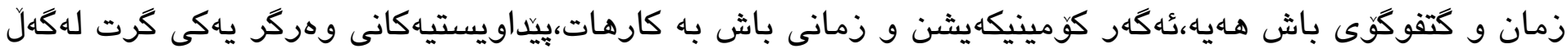

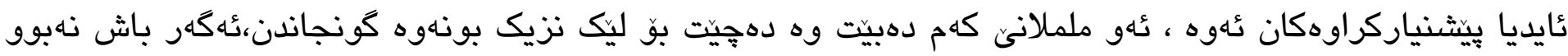

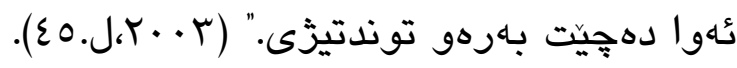

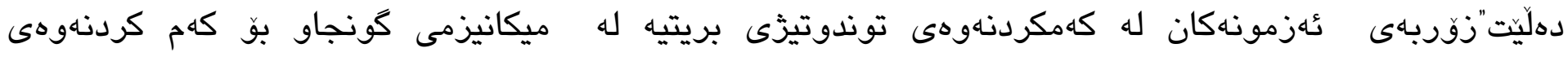

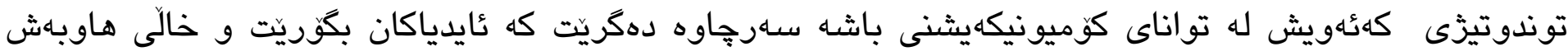

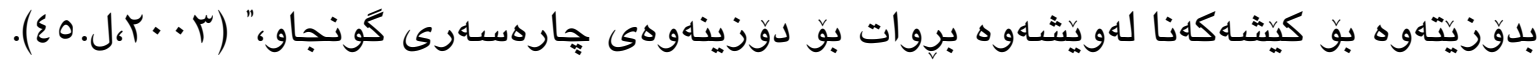

Liddicoat

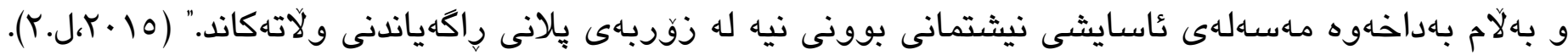




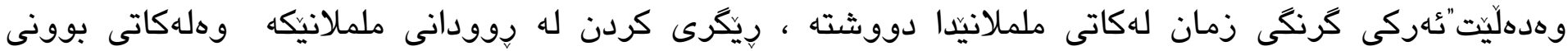

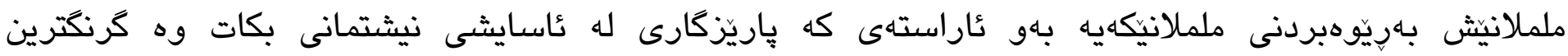

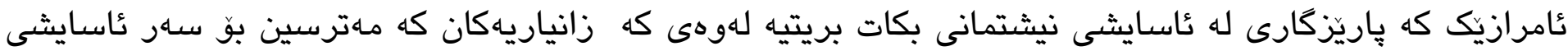

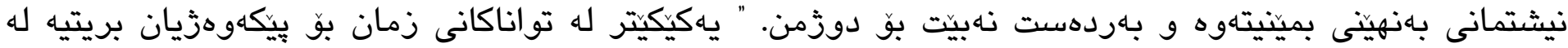

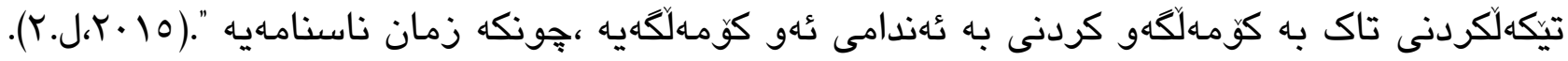

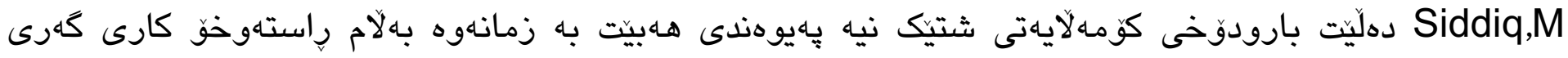

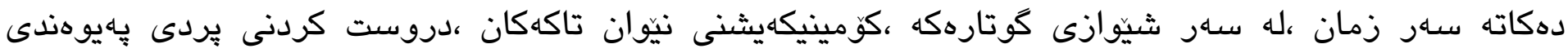

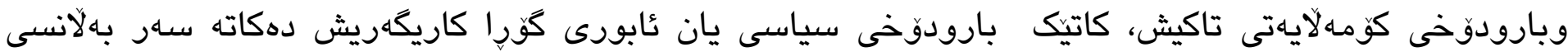

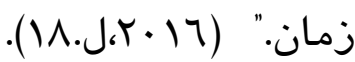

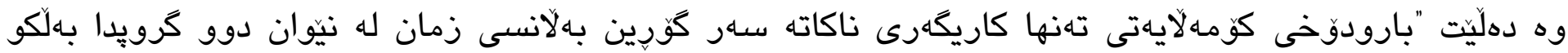

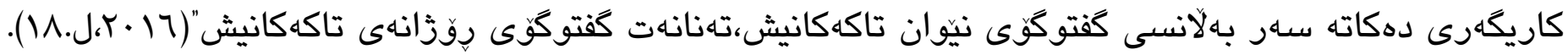

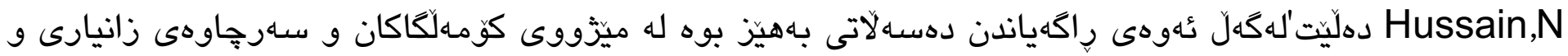

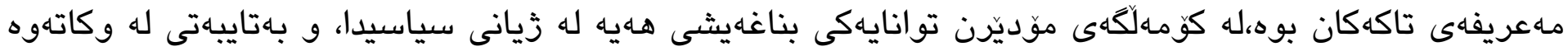

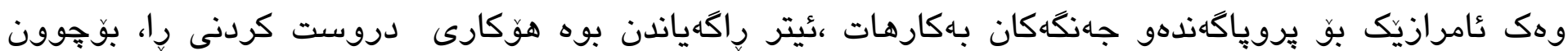

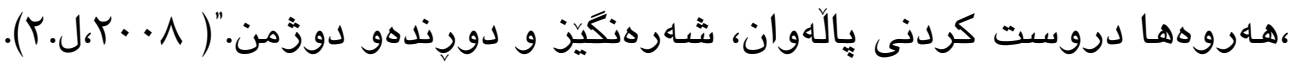

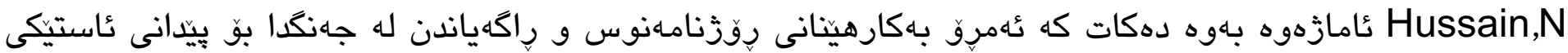

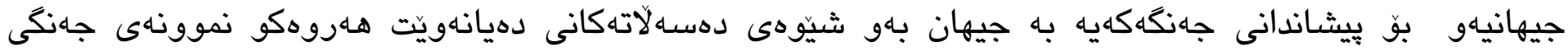

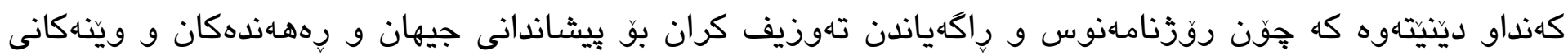

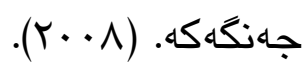

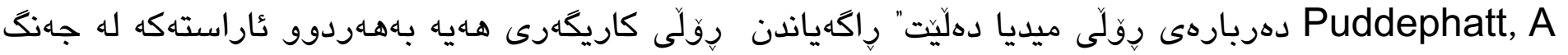

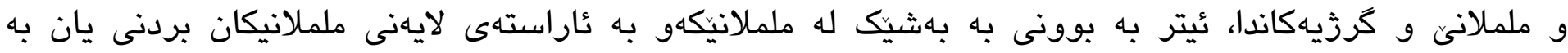

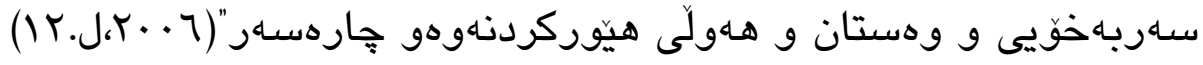

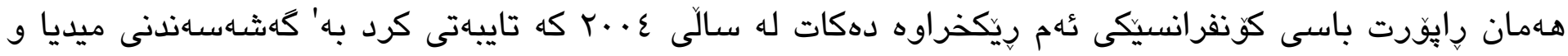

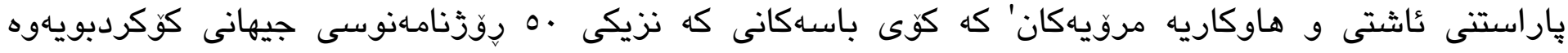

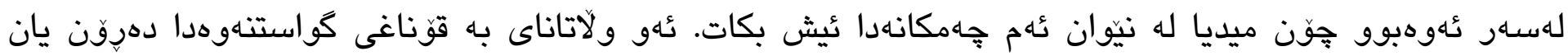

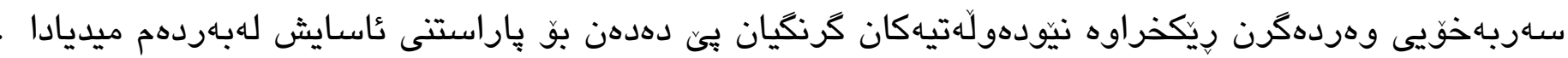
خussain,N

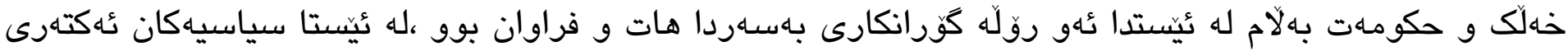




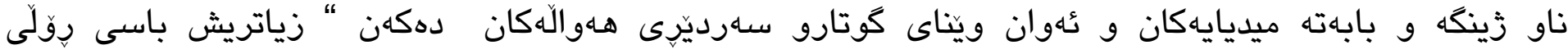

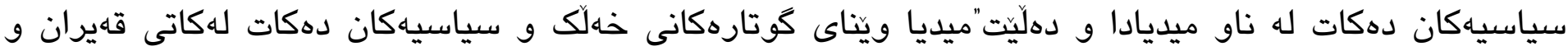

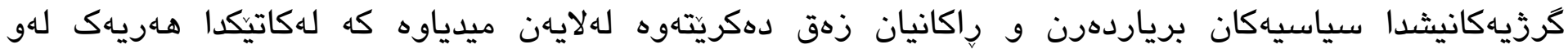

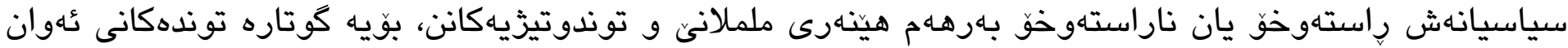

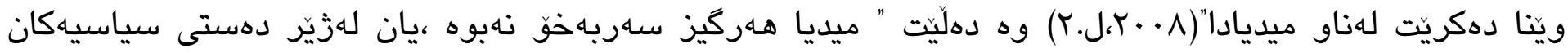

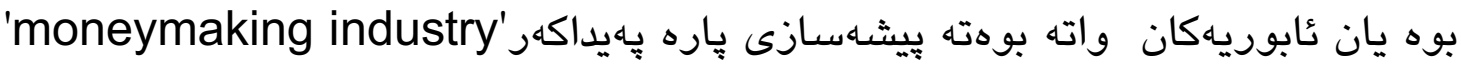

Hussain,N

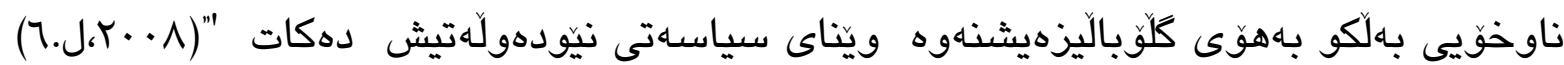

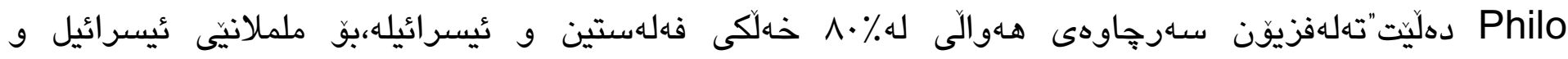

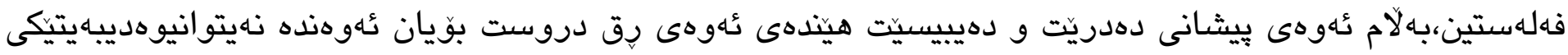

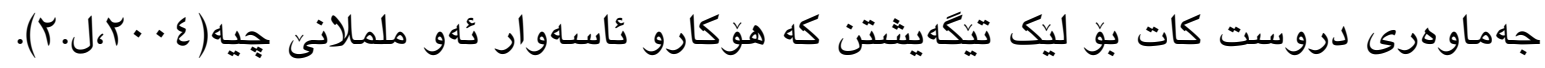

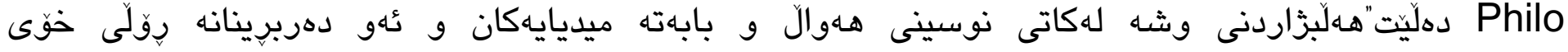

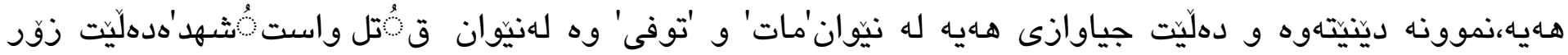

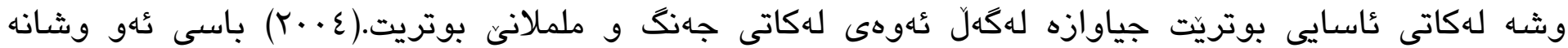

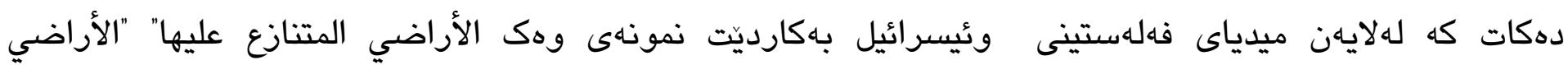

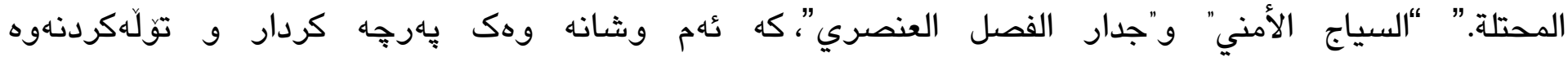

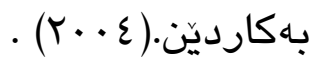

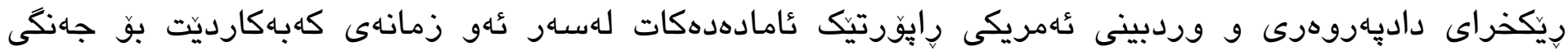

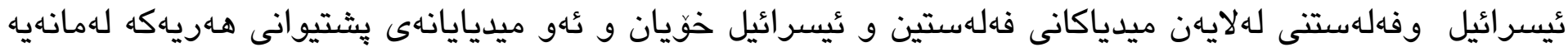

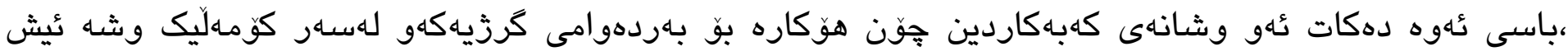
دهكات لهوانه:

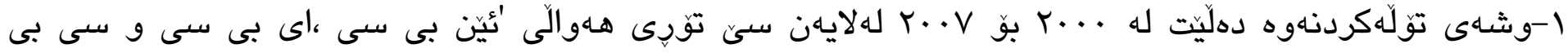

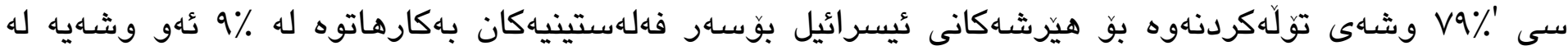

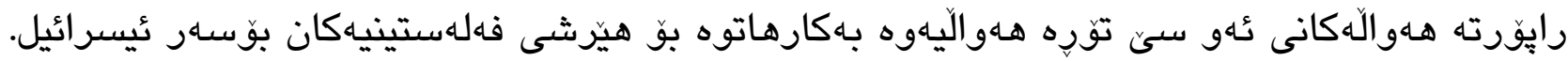

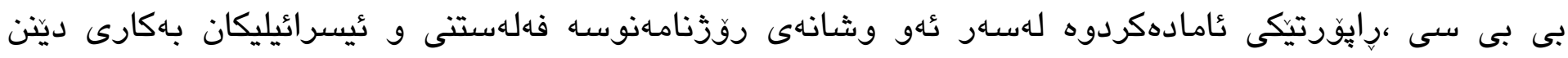

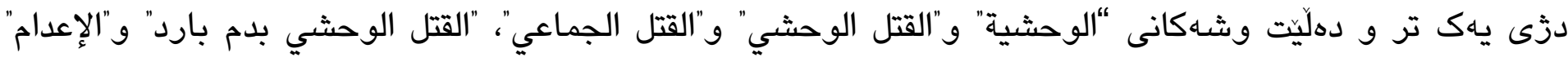

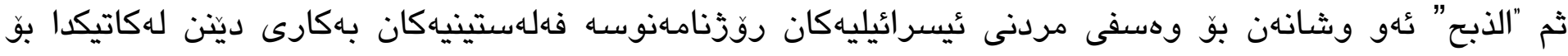




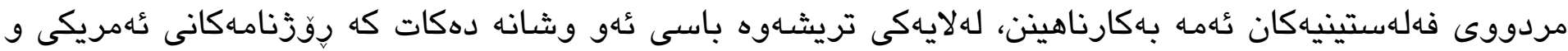

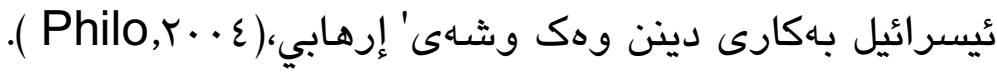

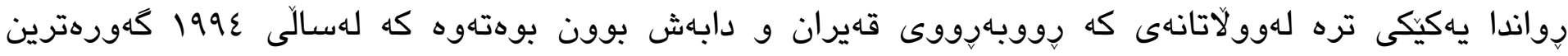

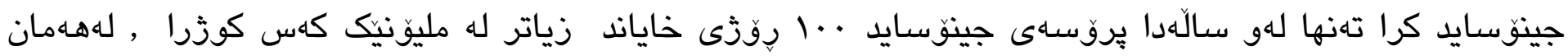

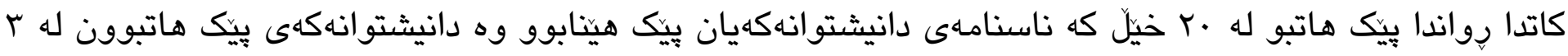

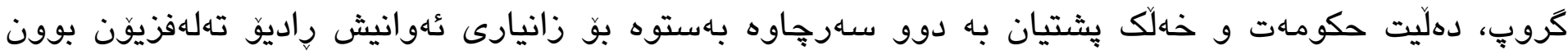

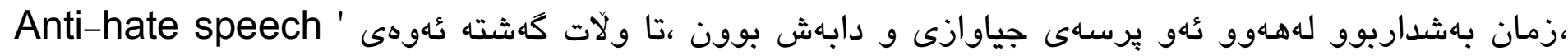

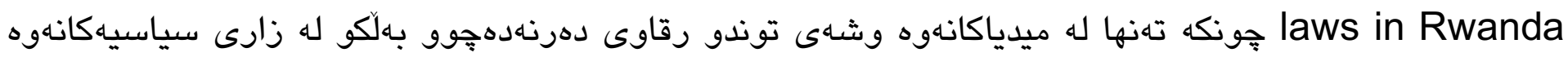

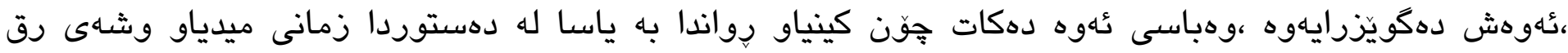

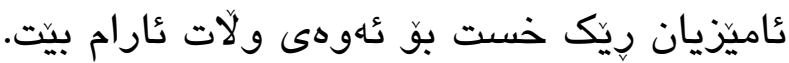




\section{بلاشى سييّهم :لايلهن مهيدانى}

\section{ا-ץ:خسته נפوى ثلهنجام و تاوتوى كردنيان:}

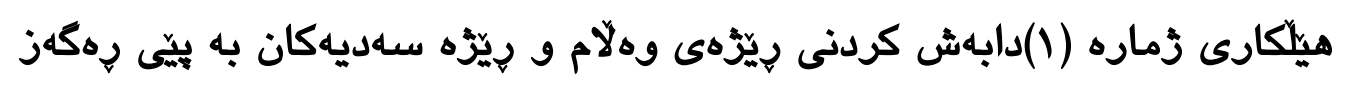
Points scored

ز50,

22 responses

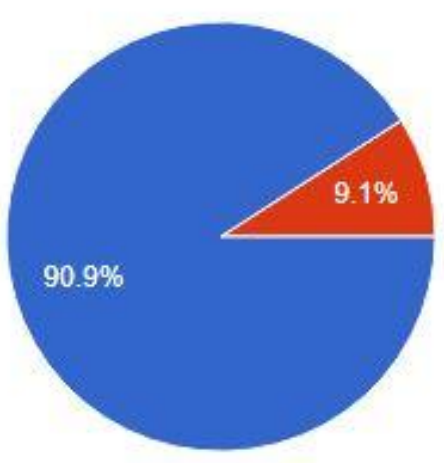

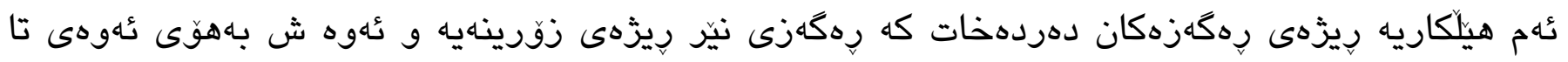

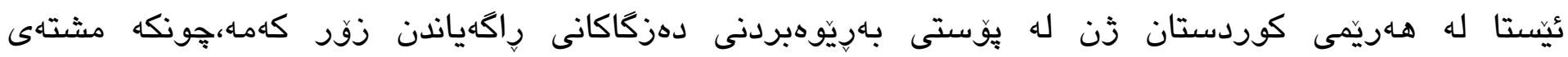

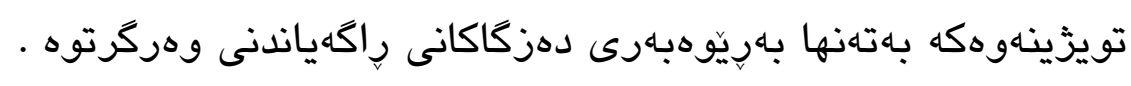




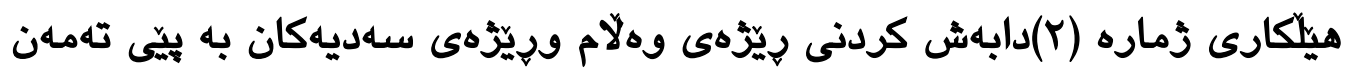

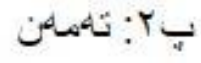

22 responses
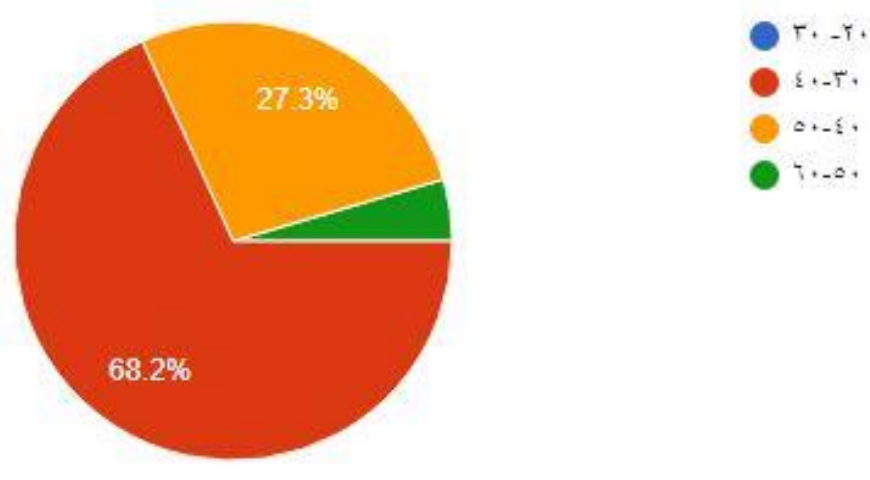

?...

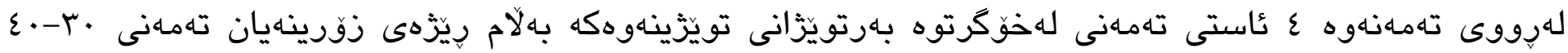

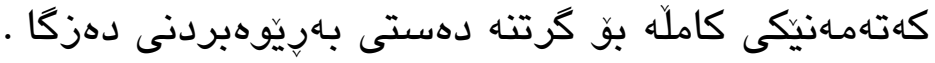




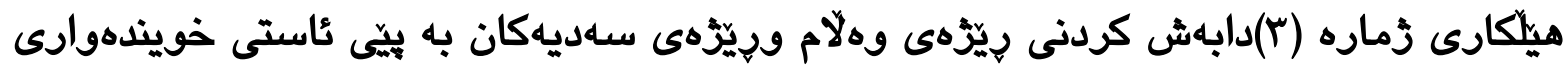

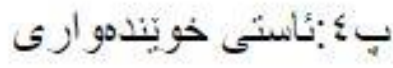

22 responses
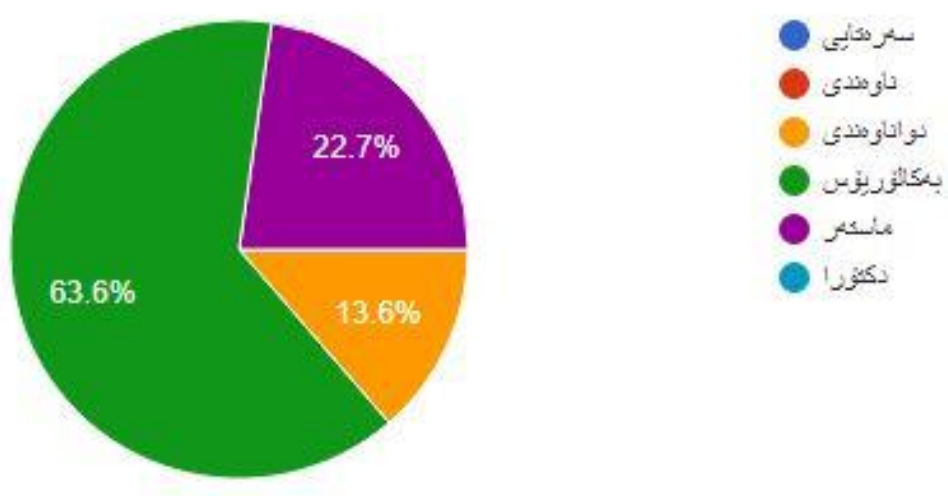

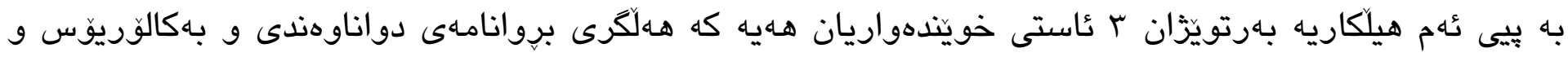

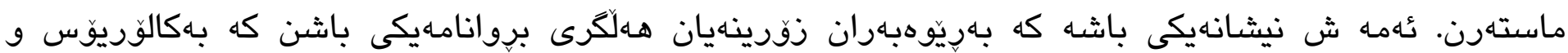
دواتر ماستهره. 


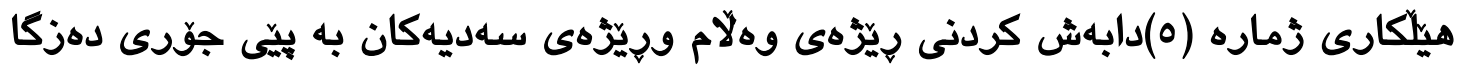

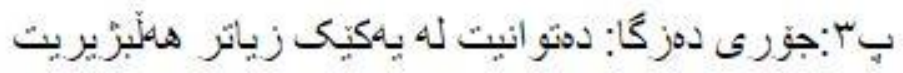

22 responses
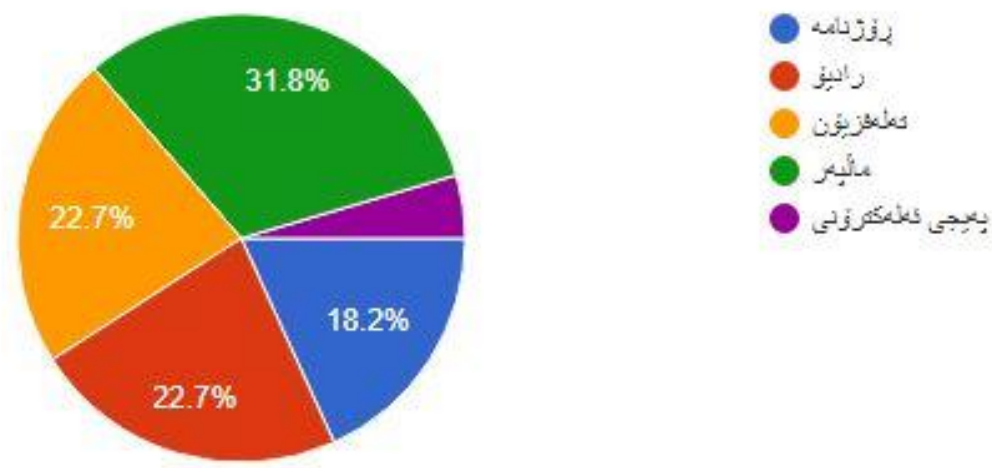

ئهوهى باشه به كَتتكيرى تويزّينهوهكه كه بهرتويزان لهدهزكا جوراوجورهكانى راكهياندن بهشداربوون له

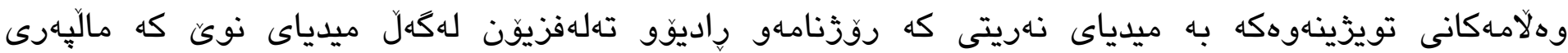

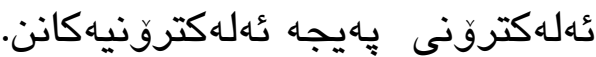




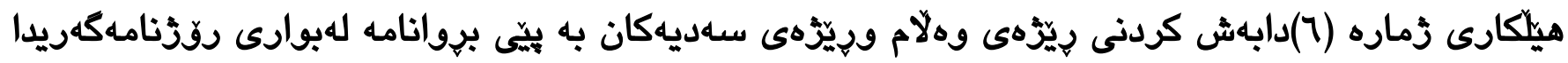

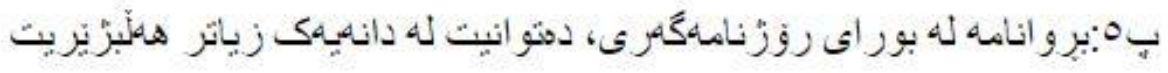

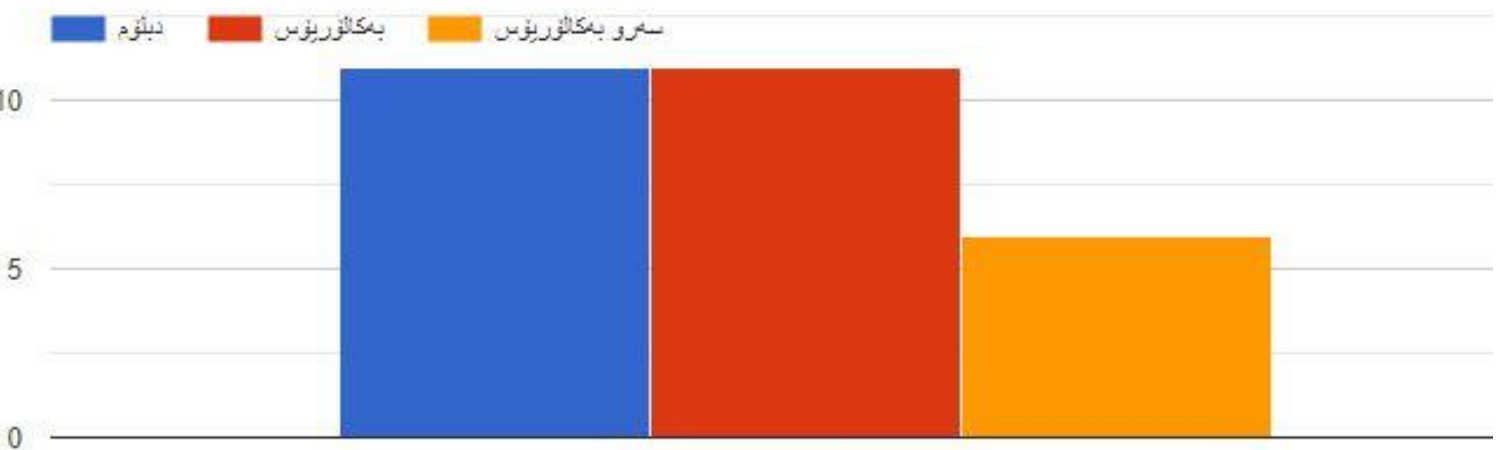

Row 1

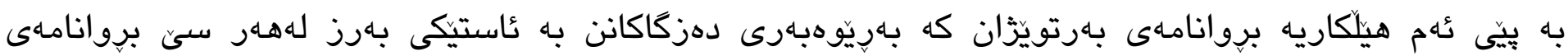

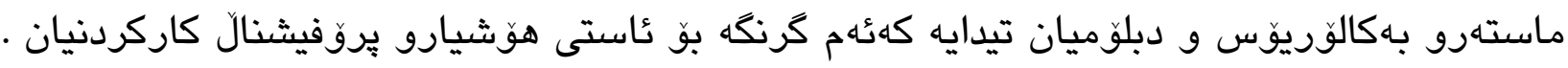




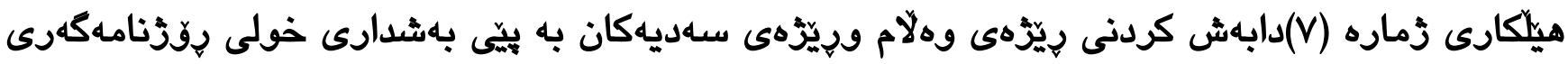

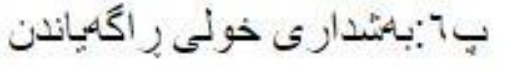

22 responses

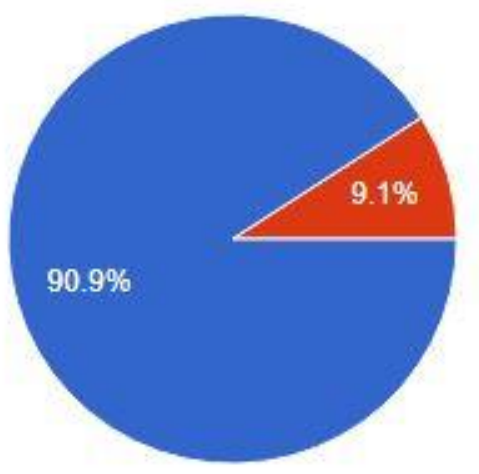

بكنئ

Oن

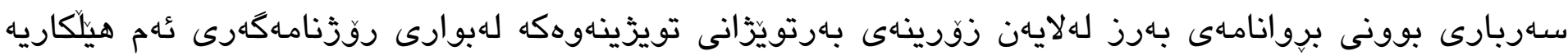

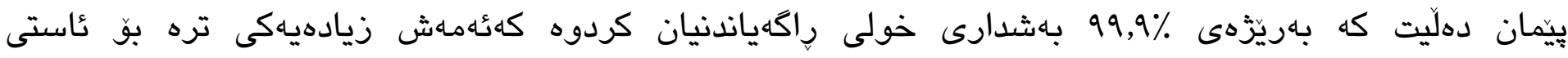

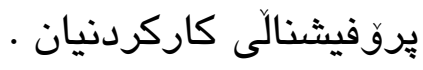




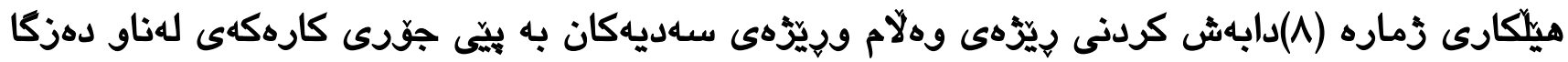

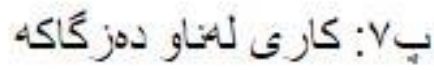

\section{2 responses}

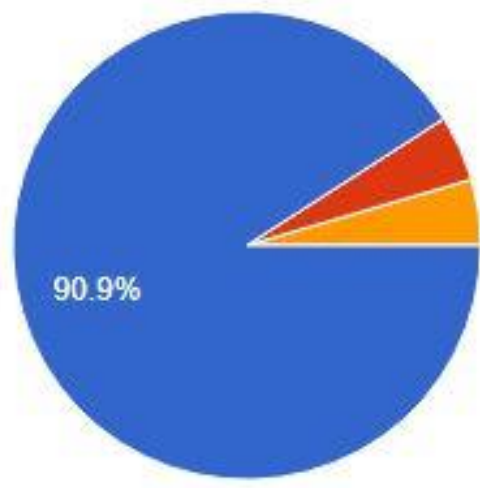

بكرئوبير-

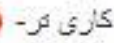

serbari kara sarkiyaakam peshkashkar

لهبهر ئهوهى ئامانجى تويزينهوهكه بهإيّوهبهرى دهزككانى به مشتهى تويزينهوهكه وهركرتبوو جونكه ئهوان

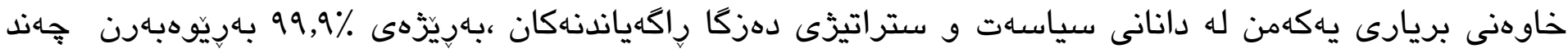

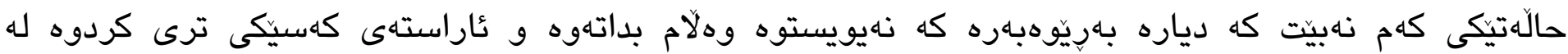

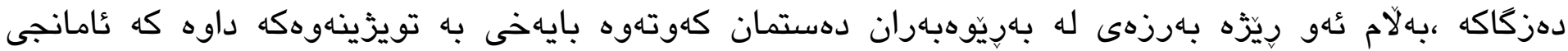
بإِريوهبهران بوه. 


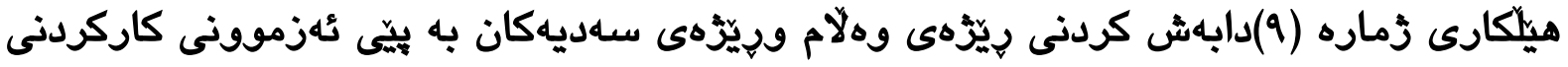

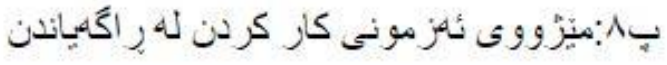

22 responses

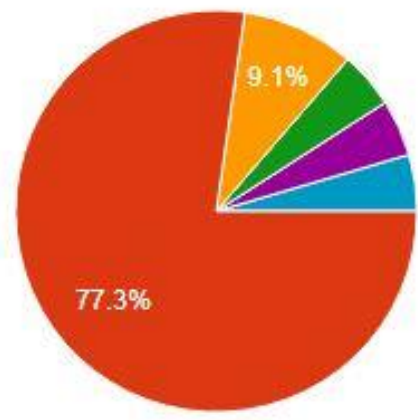

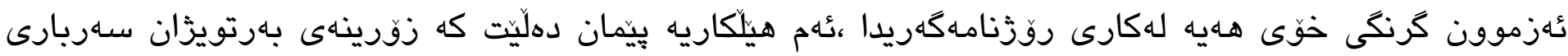

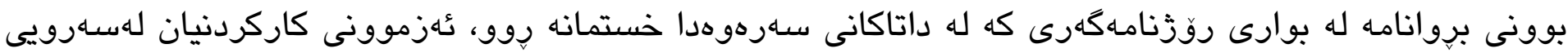

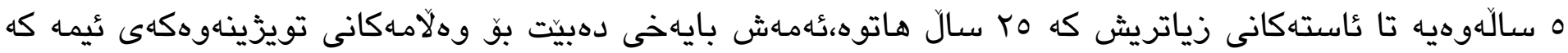

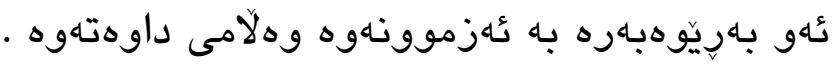




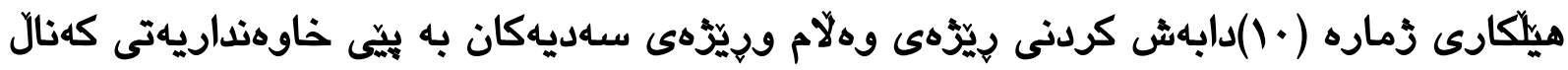

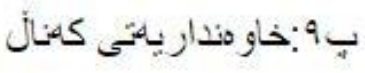

22 responses

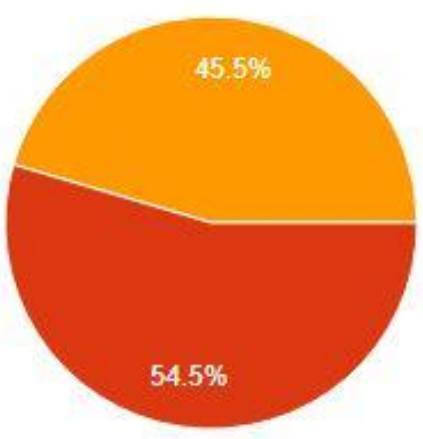

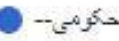

حبزبي-

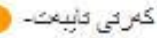

$54.5 \%$

خاوهندارياهى كهنال روّلى هـايه لهدياريكردنى سياسهات و ستراتيزهكهى،وهبهتايبهتيش له دروست كردنى ئاشتى و

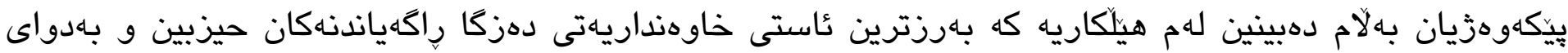

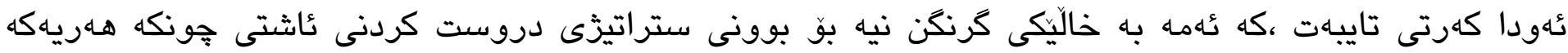

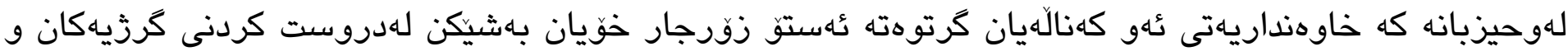

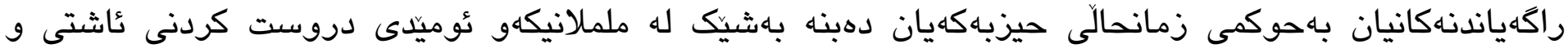

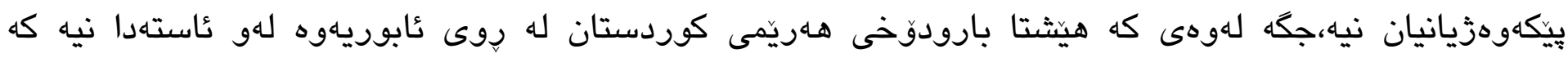

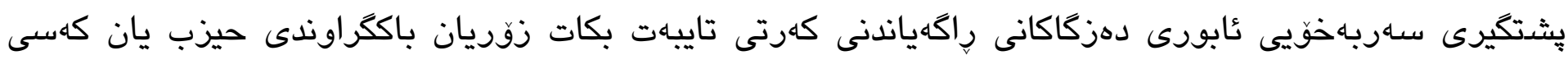

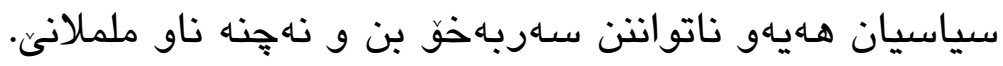


هيلكارى زماره (1)(1ابهش كردنى ريّزهى وهلام ويِّرّى سهديهكان به بيّى بوونى ستراتيز

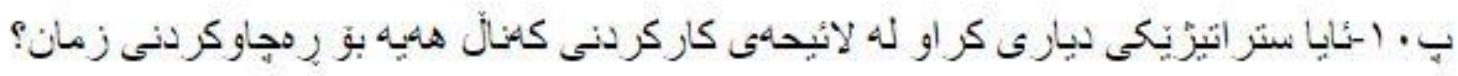

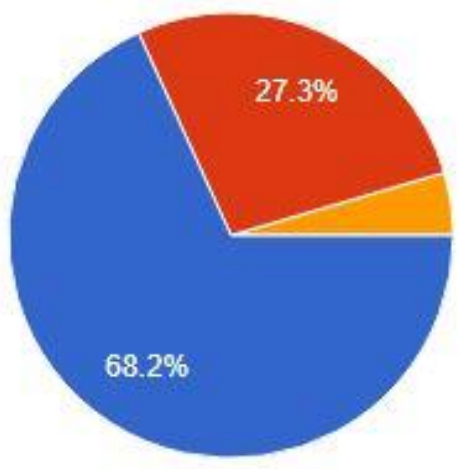

بكلئ-

(1)

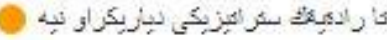

لهوهلامى بِرسيارى عايا سترتيزيكى ديارى كراو هـيه بوّ بوونى ستراتيزيكى ديارى كراو به زمان، زورينهى

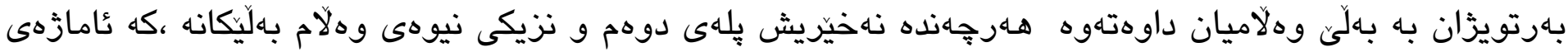

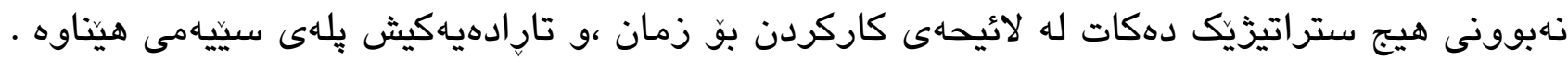




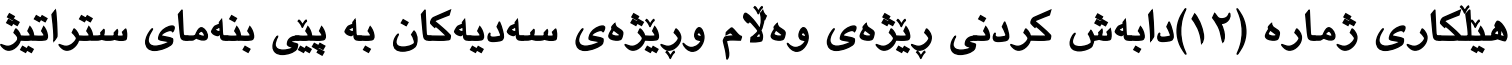

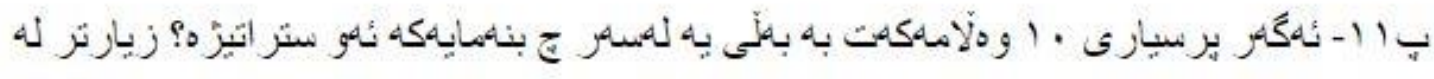

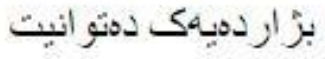

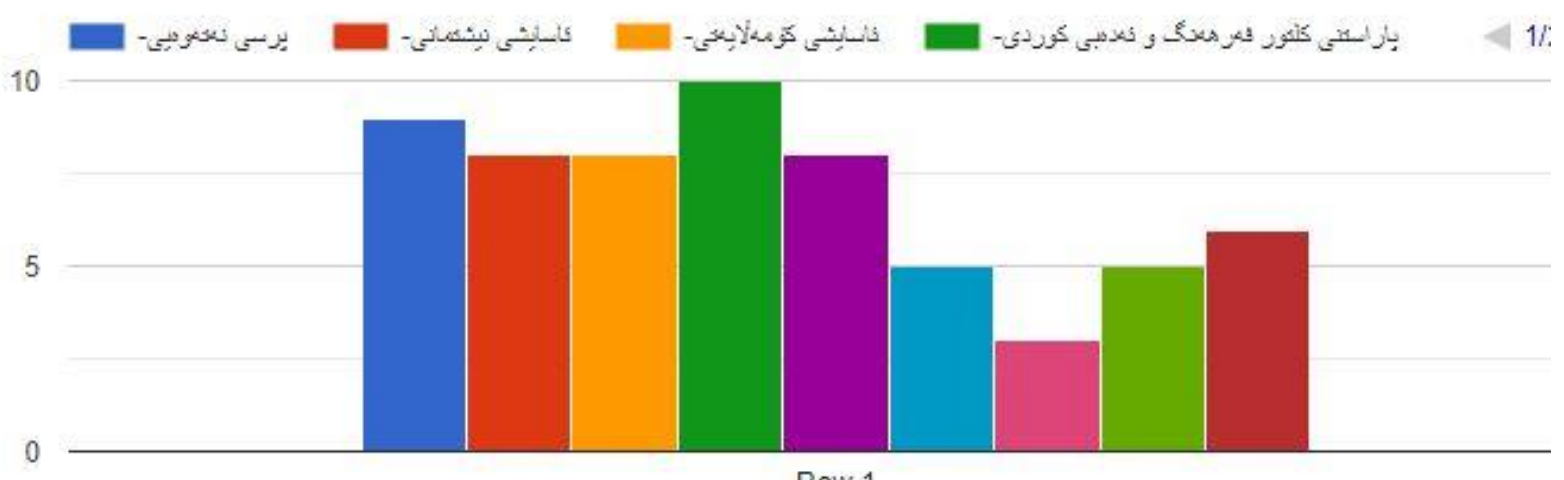

Row 1 

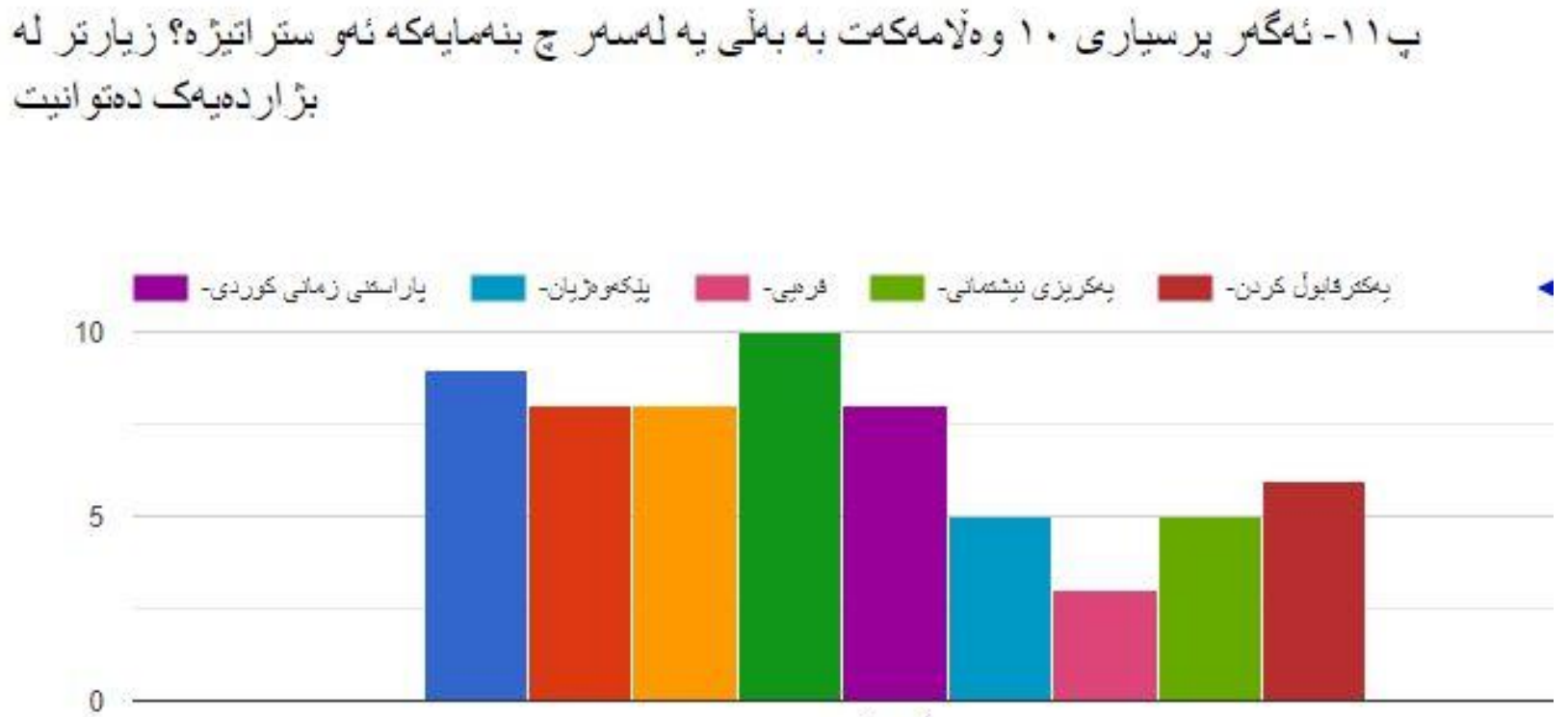

Row 1

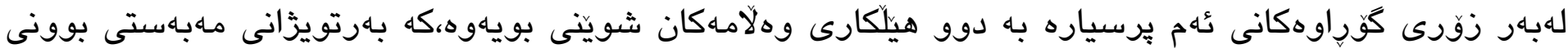

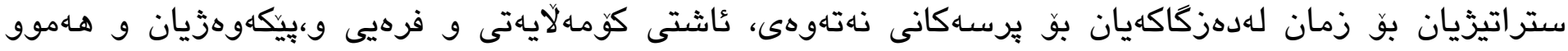

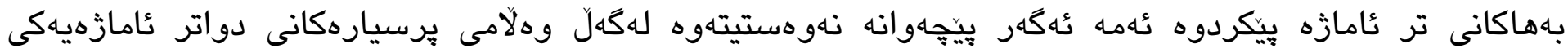

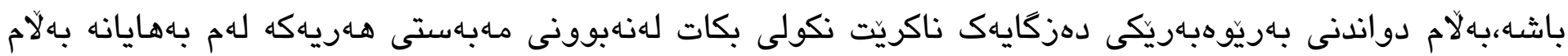

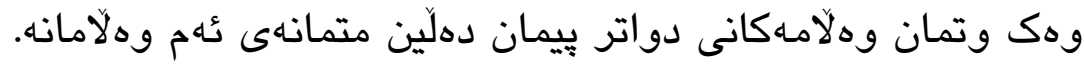

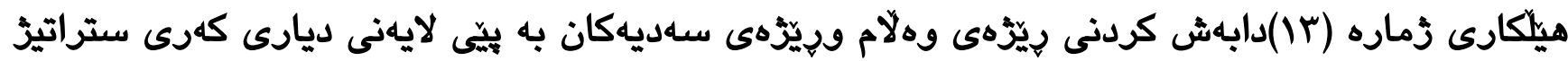




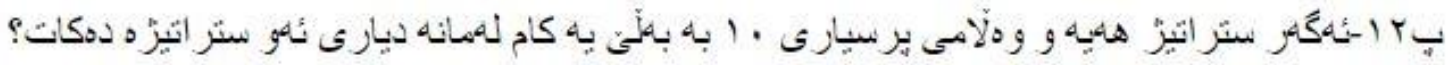

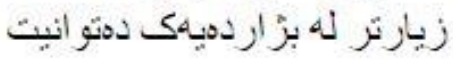

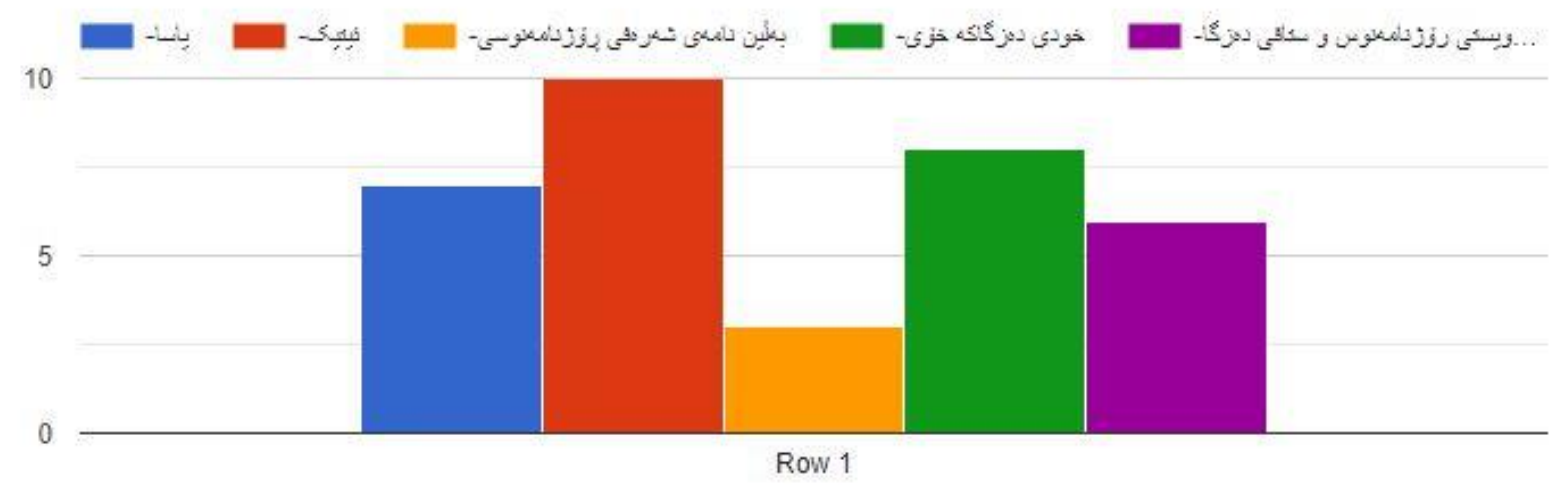

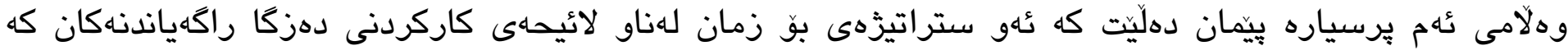

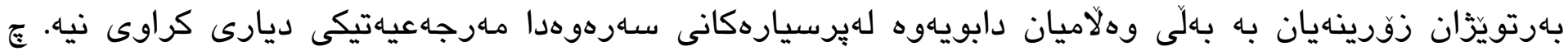

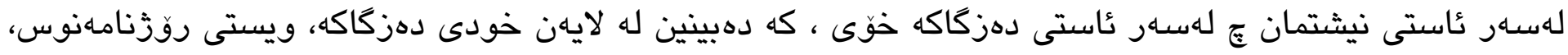

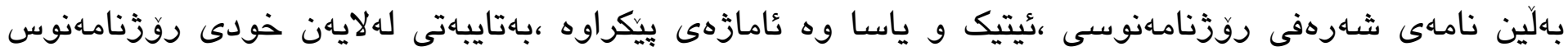

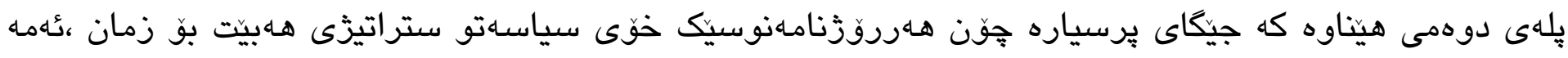

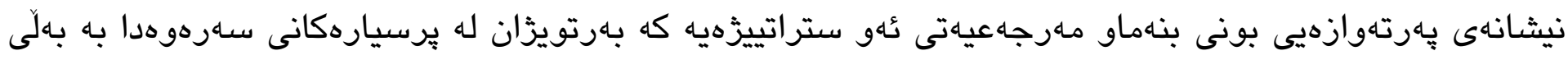
تُامازهيان بينكرد. 


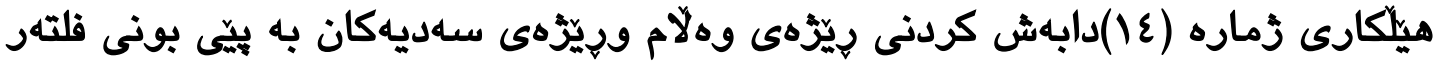

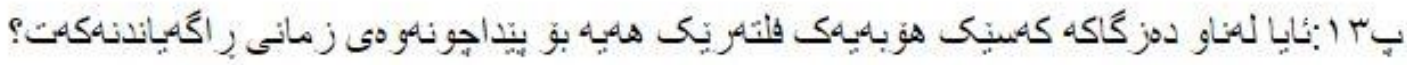

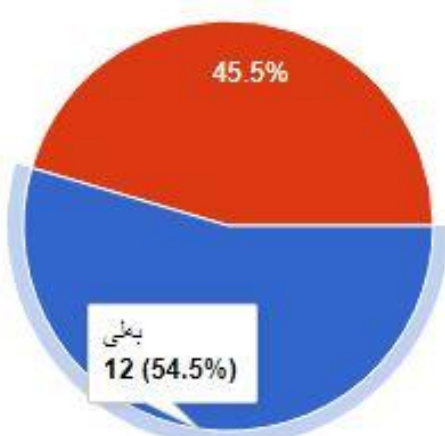

(1)

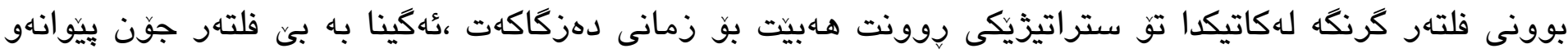

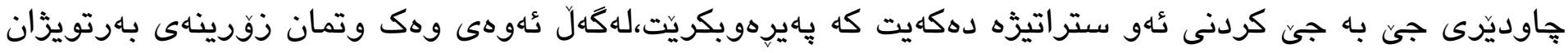

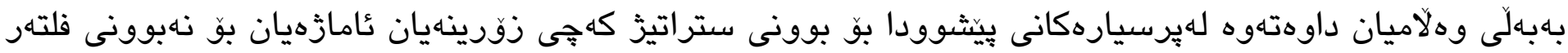

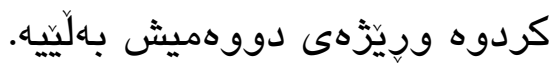




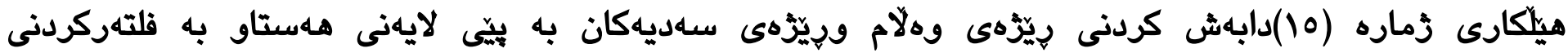

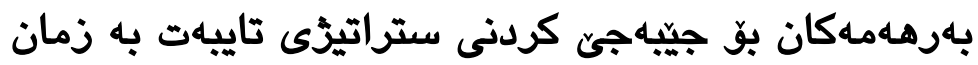

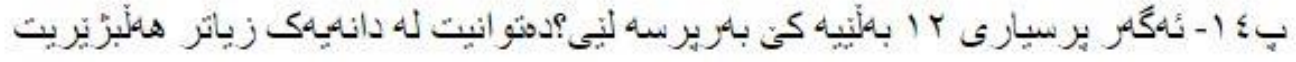

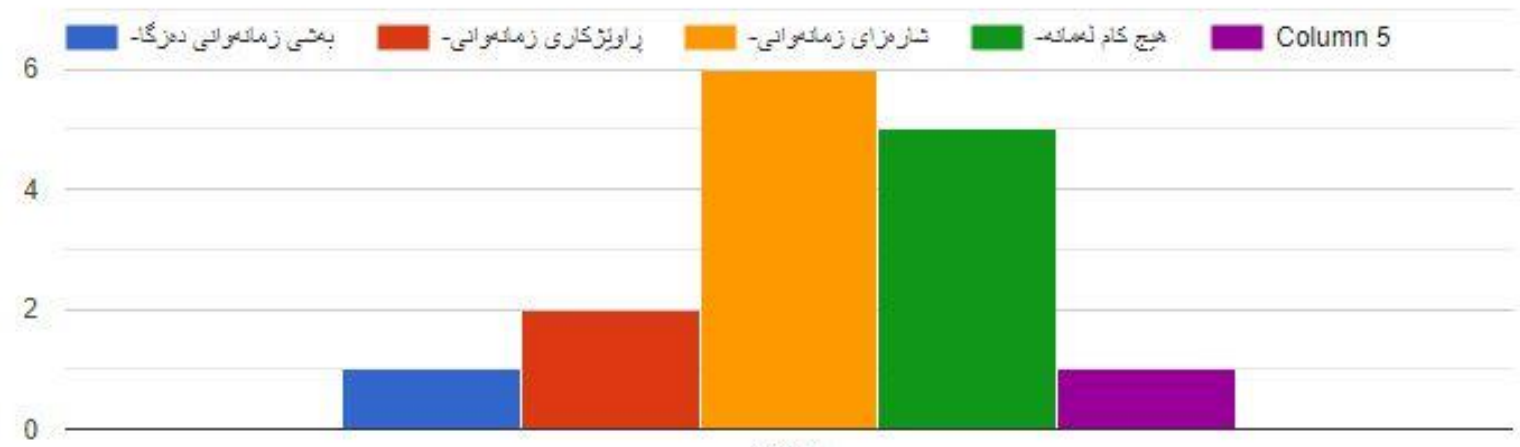

Row 1

بوّوونى سانسوّرو فلتهر كردنى بهرههمه ميديايهكان كه بلاّ دهكرينّهوه لهدهزكاكان يرسيارمان ناراستهى

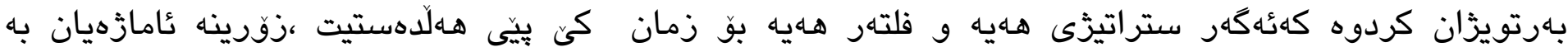

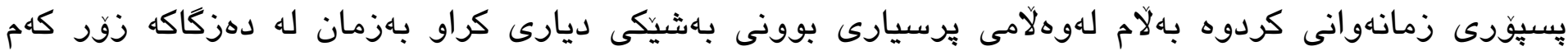

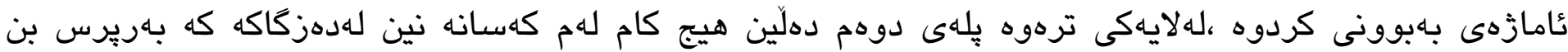

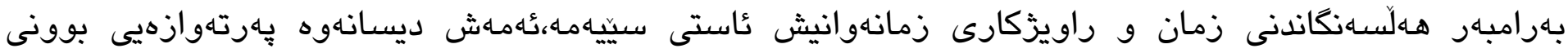

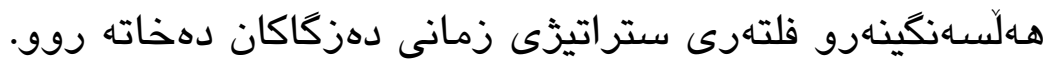




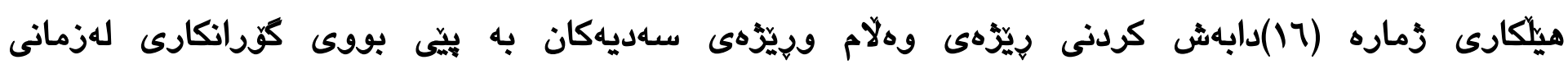

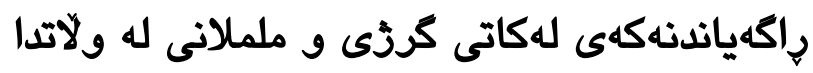

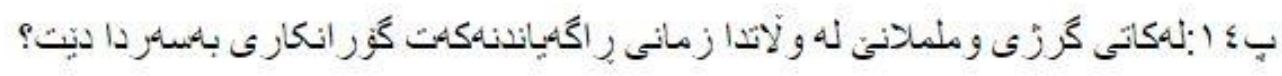
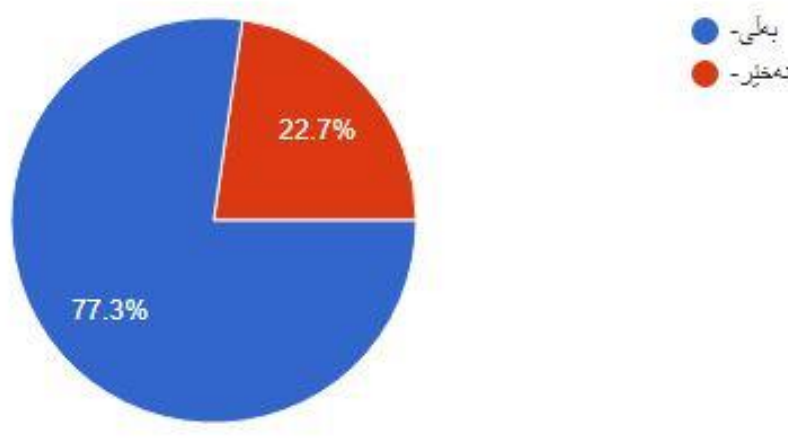

( 


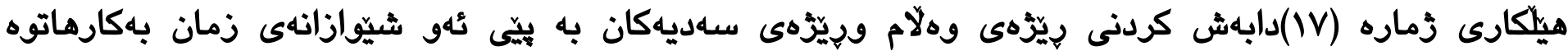
لهاتى ململانيدا

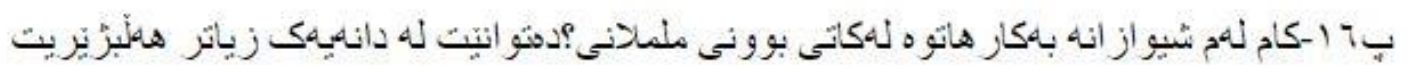

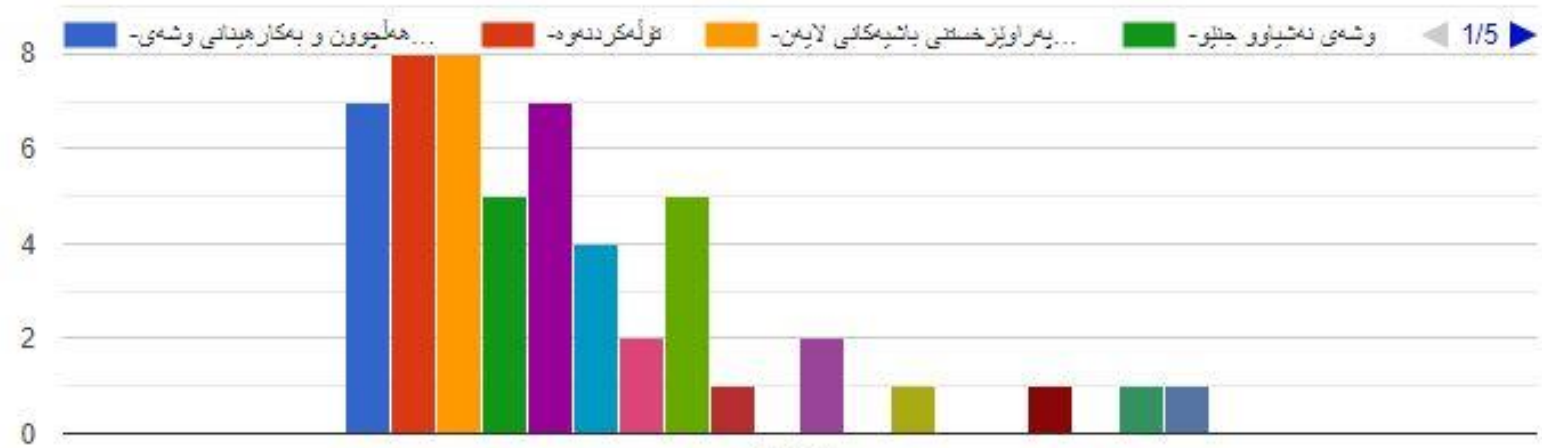

Row 1

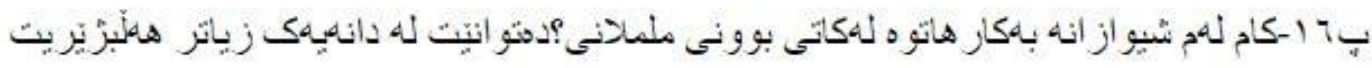

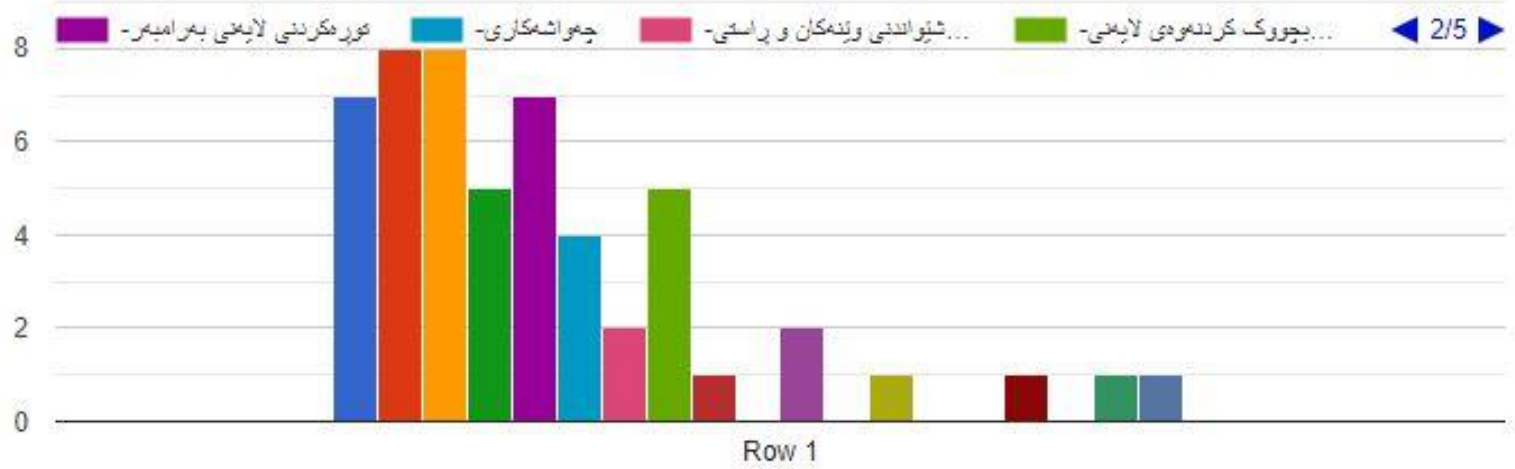




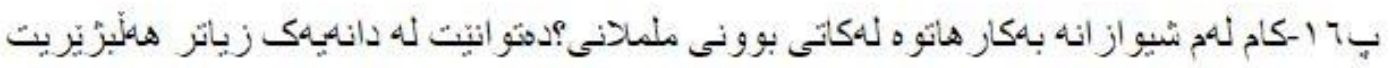

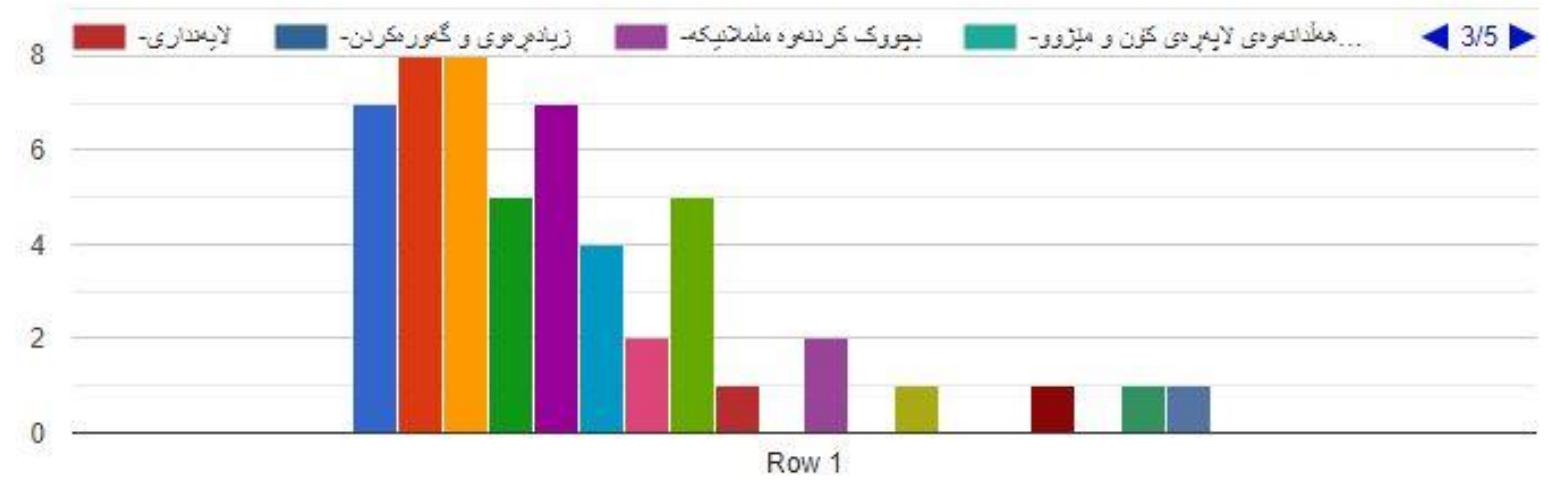

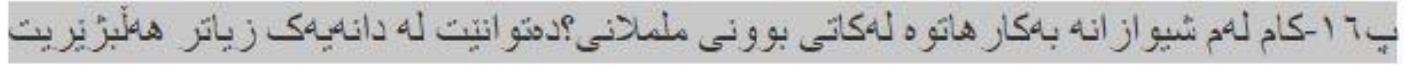

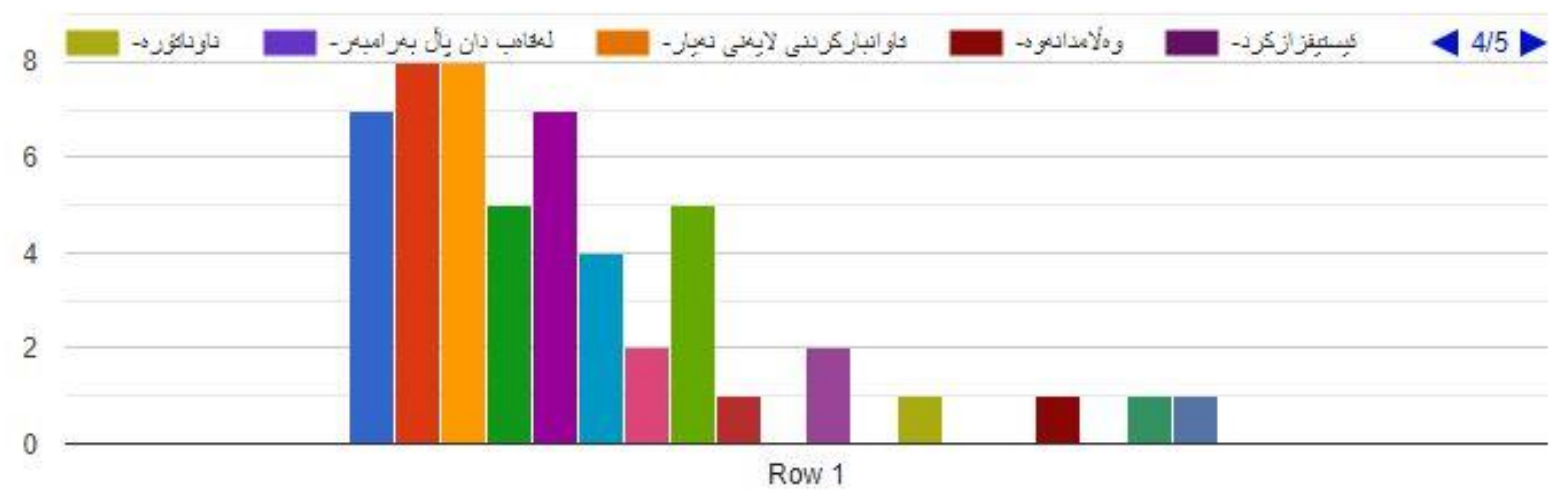




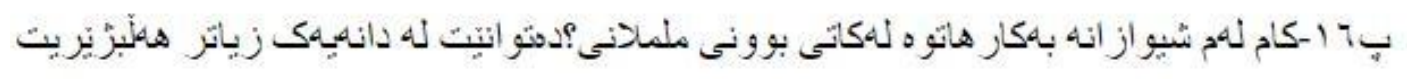

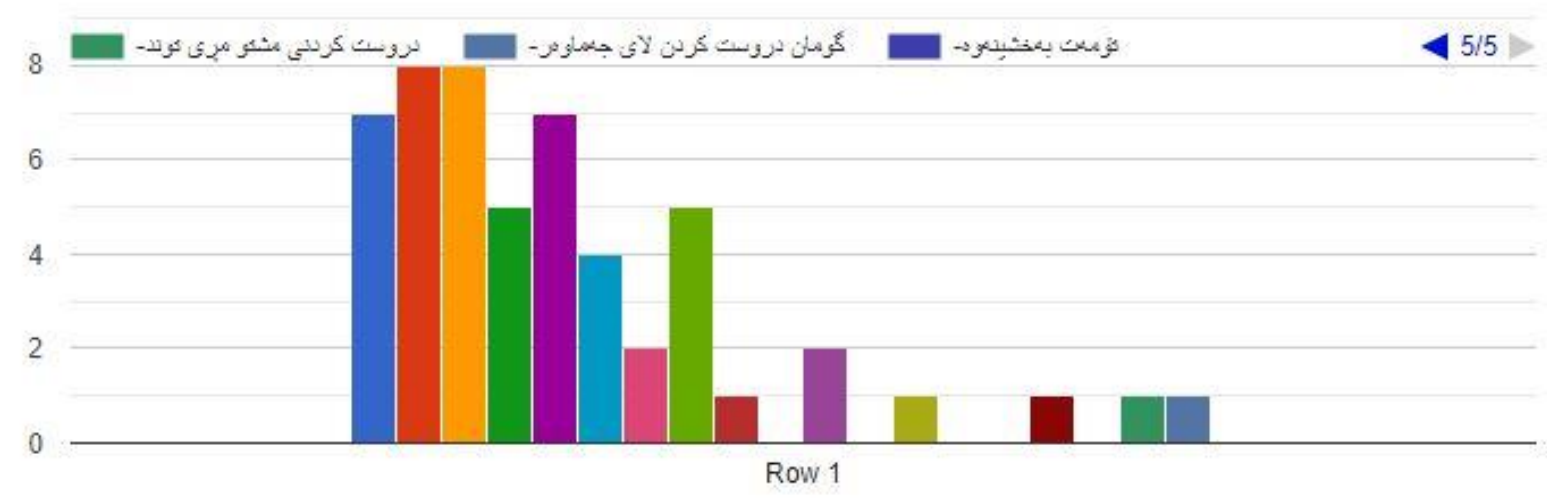

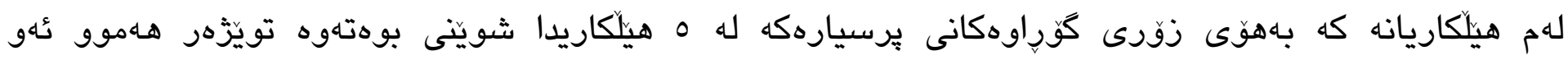

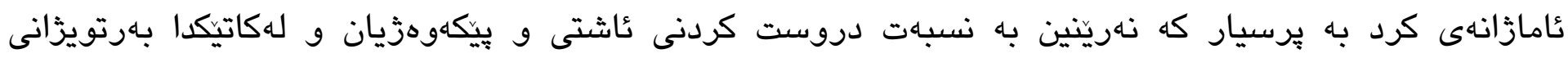

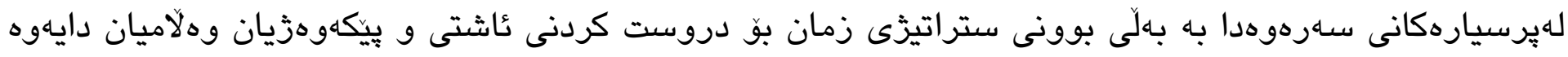

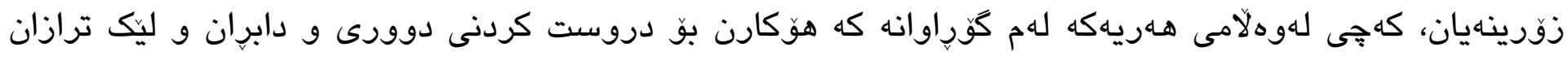

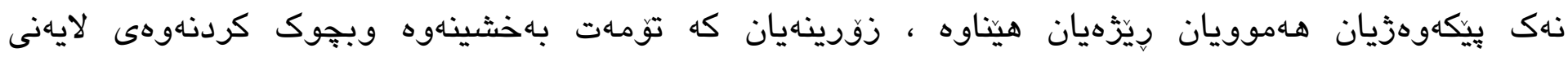

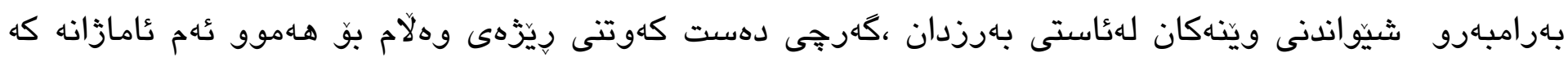

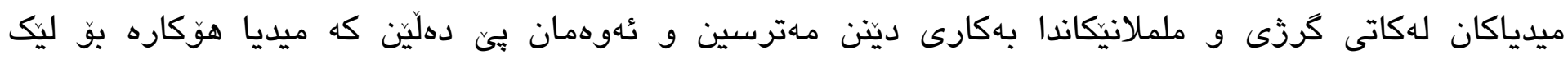

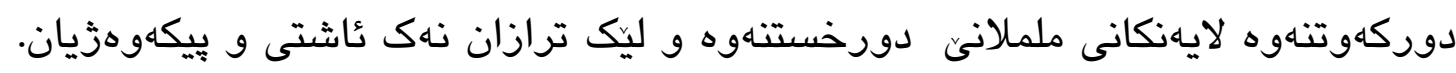




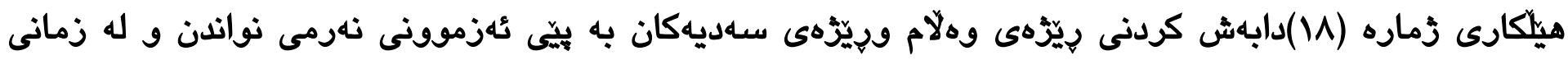

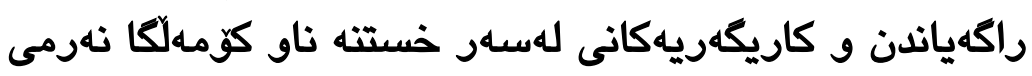

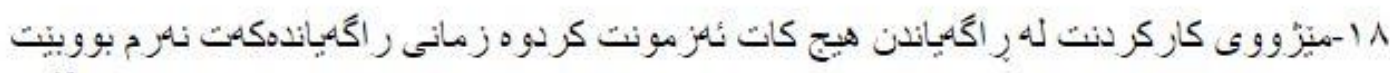

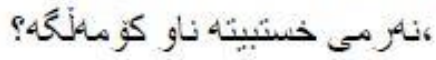
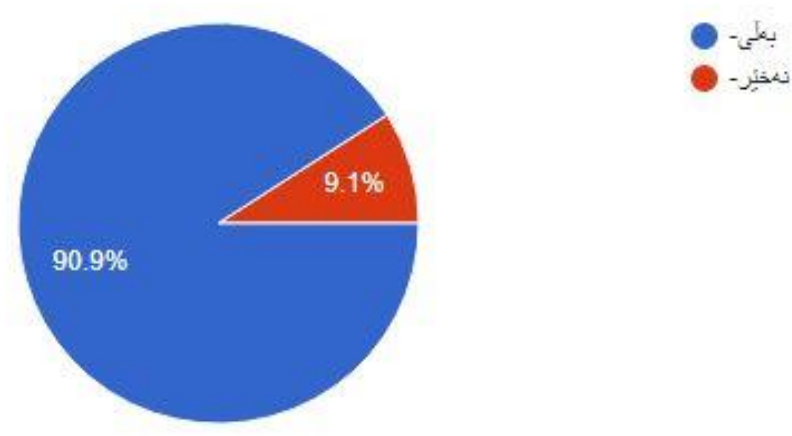

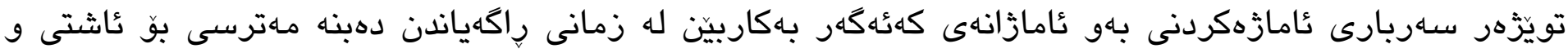

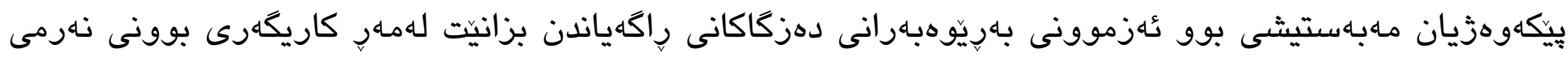

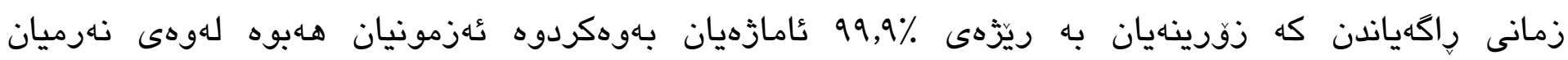

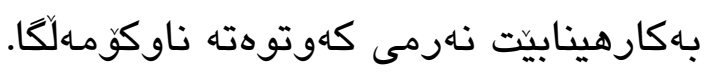




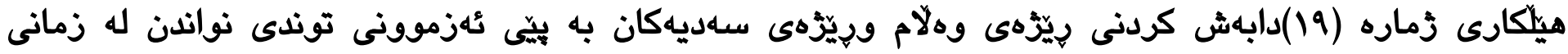

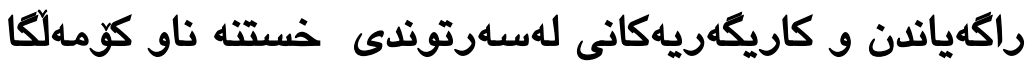

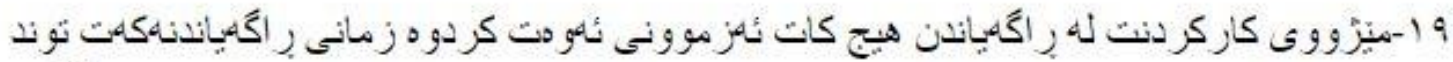

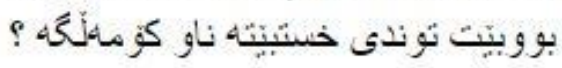

22 responses
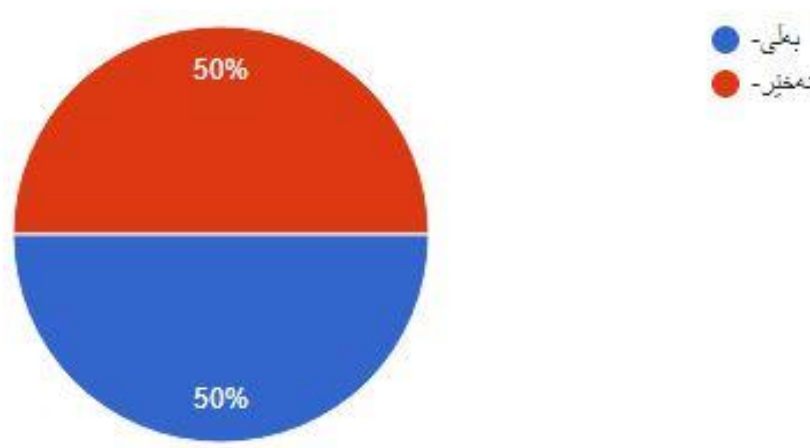

(3)

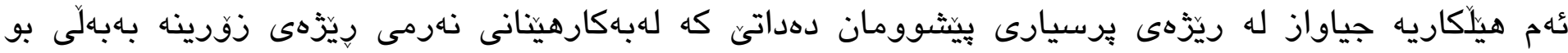

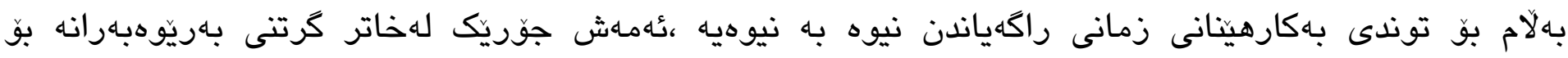

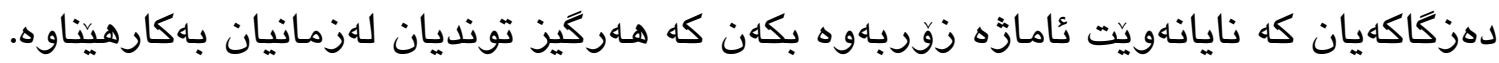




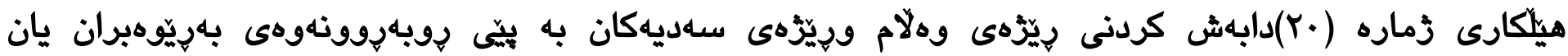

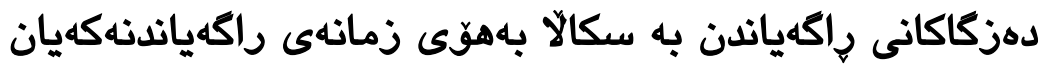

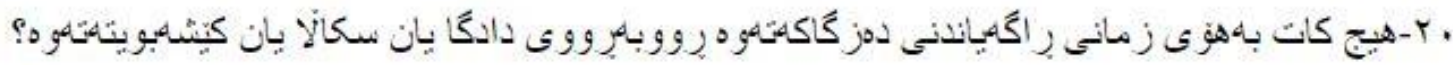
22 responses

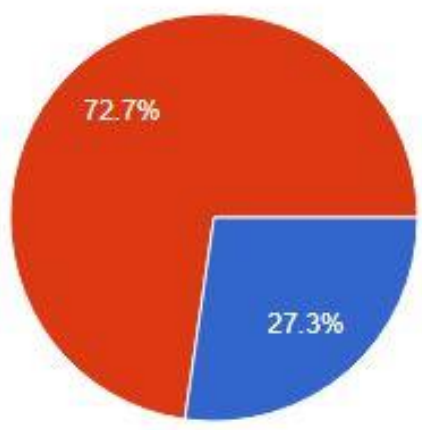

تويزهر مهابهتيهتى لهديدكاى جياوازهوه سهيرى توندى زمانى راكهياندن بكات بو دروست كردنى ئهنديثها نهك

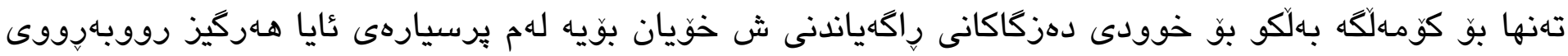

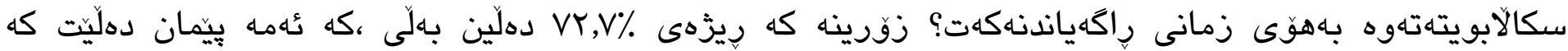

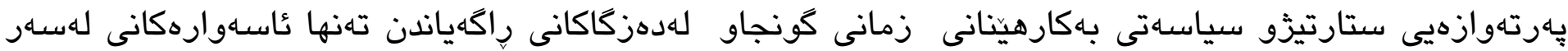

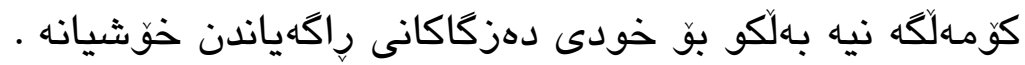




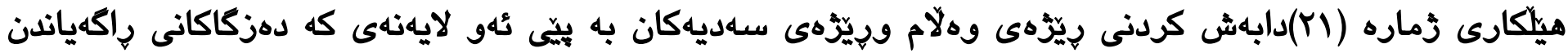

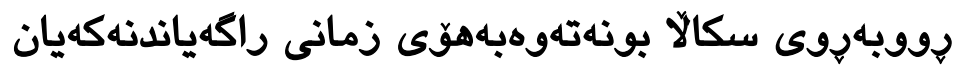

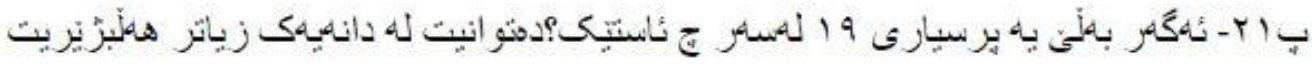

6

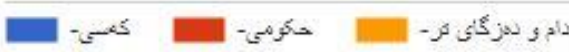
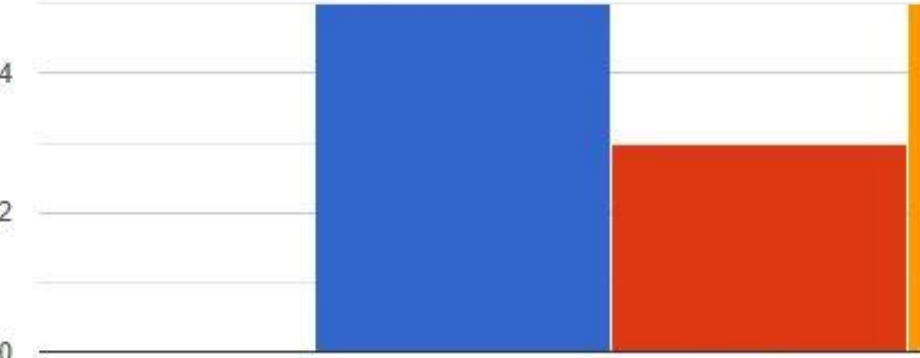

Row 1

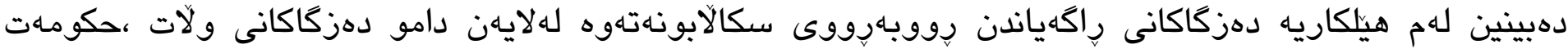

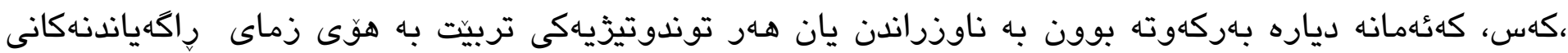

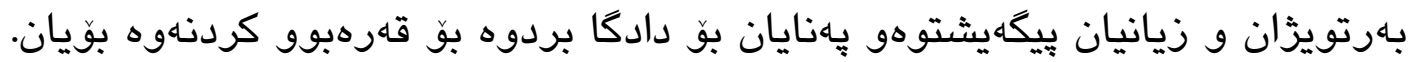




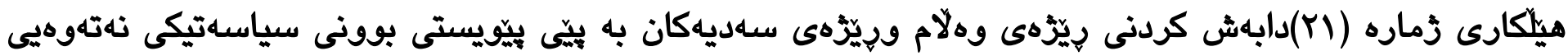

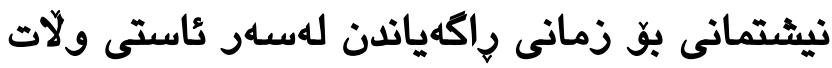

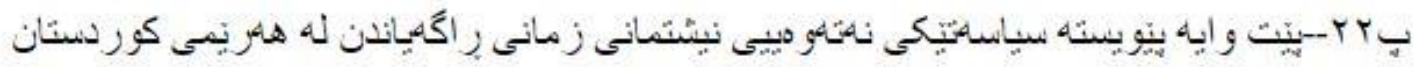
هـبيَت

22 responses

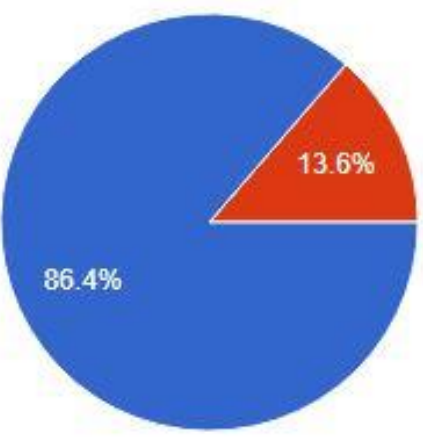

تويزهر ماهبهتى بوو ئايا يِيّوييتى بوونى سياسهات وستراتيزيكى زمانى نهتهوهيى لهسار ناستى نيشتمان هاهيه

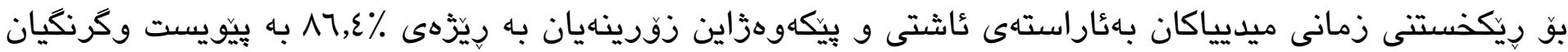
زانى. 
ا-بوونى ستراتيزيكَى رِوون بو زمان و بهكارهينانى بوّ دروست كردنى عاشتى و بيّكهوهزيان به شيّوهيهكى ريّك و

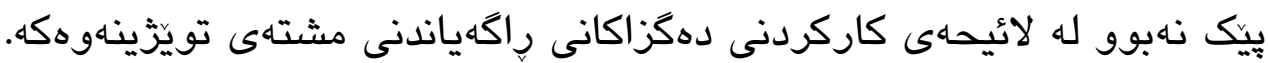

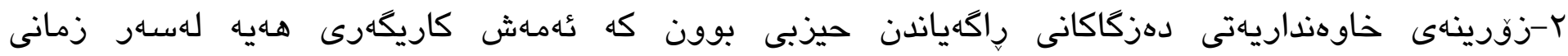

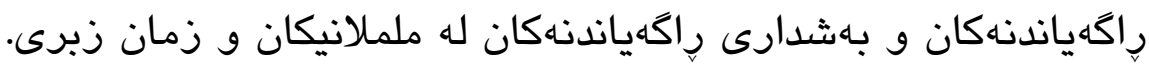

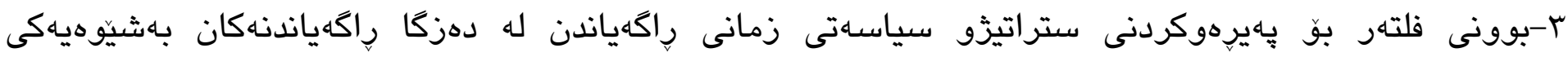

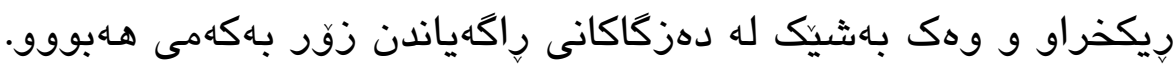

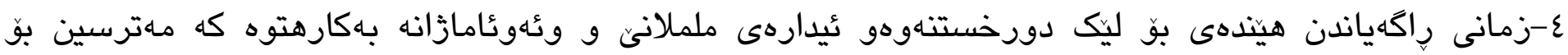

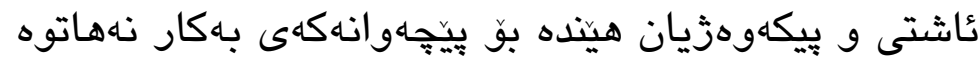

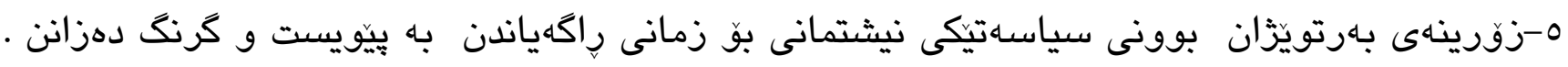

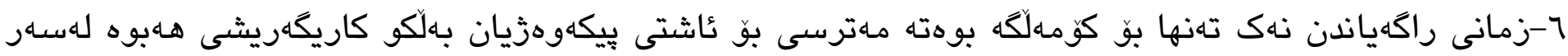

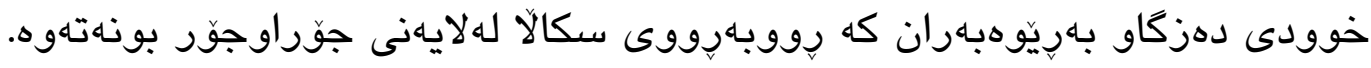

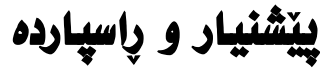

ا-بوونى سياسهتيكى نيشتمانى نهتهوهيى بو زمانى راكهياندن كه ئامانج ليّى خزماه كردن بيت به بـاشتى و بيكيكوهزيان.

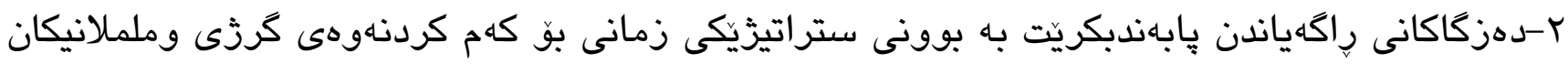

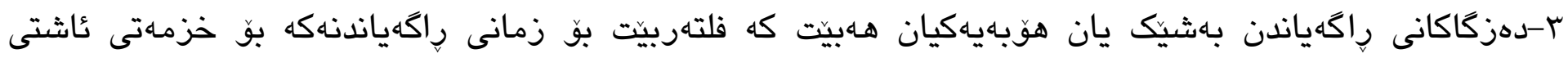
وييكهوهزيان. 


\title{
The role of media language in creating coexistence in conflict society
}

\section{Nazakat Hussein Hama saeed}

Media department, College of Humanities, University of Sulaimani , Sulaimani, Kurdistan Region, Iraq.

E-mail: nazakat.hamasaeed@univsul.edu.iq

\begin{abstract}
:
Language in most societies is a key role in creating coexistence, peace, social and security. However, this can only happen when the language is taken as an important part of the constitution and the law of that country, which have to be constituted as a way of beginning for coexistence. Furthermore, at the same time the education system and the media have also to be put to serve and create a suitable language for coexistence. The opposite is also true, where language is an identity; it is a way of dialogue, word or a term that are used. It is misunderstanding between some people in some societies that language has become a source for the mayhem, conflicts, economic crisis and the disruption of national and social security especially in those countries and societies that are passing through the transition stages. Which is also multinational, multilingual, multi faith, multi ethnic? In addition to this they also have a historical background in conflicts and war. The Kurdistan region is a newly developing region that has a diverse population and has had a historical past in continuous conflicts and war between the internal political parties. As well as this the presence of a political media system in the country has been a part of the conflicts in which has made the media language a huge reason for the distancing of the parties and the further deepening of the conflicts. That is why this research investigates the importance and role of the media language of its responsibility of creating coexists, the Kurdish channel in the Kurdistan region taken it as an example ,by using a survey method.
\end{abstract}

Key words: Role, language, coexistence, conflict 


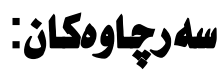

Adejimola, A. S. (2009). Language and communication in conflict resolution: Journal of Law and Conflict Resolution, 1(1), 001-009. University, Akungba-Akoko, Nigeria. University, AkungbaAkoko, Nigeria.

ACHIENG, O. (2014). Reaserch Project Submitted In Partial Fulfillment Of The Requirements For Aaward Of The Degree Of Master Of Arts In International Studies At The University Of Nairobi. REG No:-R50/74304/2014.

Crystal D. (1987). The Cambridge Encyclopedia of Linguistics. New York:, Oxford University Press.

Democratic Progress Institute.(2014). The Role of Language, Identity and the Media in Conflict Resolution.

Elworthy, S. (2012). Fighting with nonviolence. Retrieved from.

https://www.ted.com/talks/scilla_elworthy_fighting_with_non_violence?language=en.

Hussain,N. (2008). The Role of Media in National Security: A Case Study of 1998 Nuclear Explosions by Pakistan Copyright @ S South Asian Strategic Stability Institute Ltd, 2008.

Fairclough, N. (2001). Language and Power (2 edition). Harlow, Eng. ; New York: Routledge6

Liddicoat· Anthony J.(2015). Language planning and questions of national security: An overview of planning approaches, Research Centre for Languages and Cultures Education, School of International Studies, University of South Australia.

Moulton, S.(2004. Language by Classification, By April McMahon, Robert McMahon

Pagel, M. (n.d.). (2011).How language transformed humanity. Retrieved from http://www.ted.com/talks/mark_pagel_how_language_transformed_humanity

Philo,G.(2004). The media \& the Israeli-Palestinian conflict, Guardian, 14 July The Role of Media in National Security: A Case Study of 1998.

Puddephatt, A.(2006).conflict and the role of media, International Media Support report . 492 
Riaz, S(2017).ROLE OF MEDIA IN PROMOTING PEACE AND HARMONY, Department of Mass Communication, Allama Iqbal Open University, Islamabad.

Sapir,E. (1963). Language - An Introduction to the Study of Speech. New York: W.W. Norton and Company.

Shannon C, Weaver W. (1977). The Mathematical Theory of Communication in The Process and Effects of Mass Communication,

Communication in The Process and Effects of Mass Communication, Illinois Press.

Siddiq, M. R(2016). "Peace, Conflict, and Language: Coping with Linguistic Intolerance and Violence” MA TESOL Collection. 715. Nuclear Explosions by Pakistan

Shannon C, Weaver W. (1977). The Mathematical Theory of Communication in The Process and Effects of Mass Communication, ed. W. Schram and D. F. Roberts, 412-428. Illinois: University of Illinois Press.

Shipley J. (1970). Dictionary of World Literary Terms. London: George, Allen and Unwin. The Longman Dictionary of Contemporary English(1995). London: Longman Publishers.

Timothy‘A‘E، (2016)‘Language and communication conflict in Nigeria: Implications for communicative language pedagogy, University of Calabar

John Paul Lederach(2003). Summary of "Of Nets, Nails, and Problems: The Folk Language of Conflict Resolution in a Central American Setting" by: Mariya Yevsyukova, Conflict Research Consortium. 